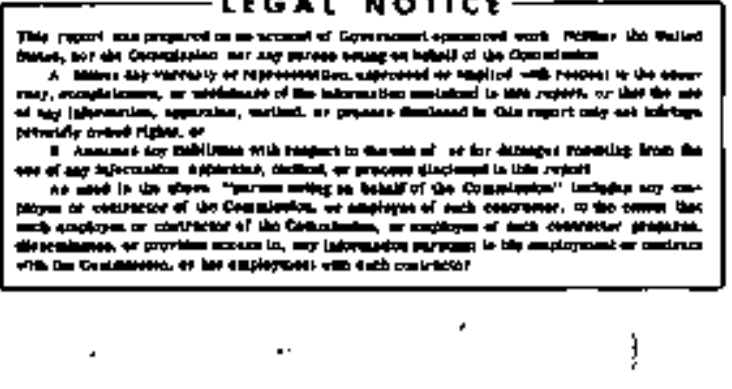

\title{
SPECIFICATIONS AND FABRICATION PROCEDURES FOR PM-2A CORE II NEUTRON ABSORBER SEC'TIONS
}

Materials Technology Branch Nuclear Power Engineering Department

Issued: May 13, 1960

Contract No. AT(30-3)-326

with U.S. Atomic Energy Commission New York Operations Office

ALCO PRODUCTS, INC. Post Office Box 414 Schenectädy 1, Nẻw York 


\section{DISCLAIMER}

This report was prepared as an account of work sponsored by an agency of the United States Government. Neither the United States Government nor any agency Thereot, nor any of their employees, makes any warranty, express or implied, or assumes any legal liability or responsibility for the accuracy, completeness, or usefulness of any information, apparatus, product, or process disclosed, or represents that its use would not infringe privately owned rights. Reference herein to any specific commercial product, process, or service by trade name, trademark, manufacturer, or otherwise does not necessarily constitute or imply its endorsement, recommendation, or favoring by the United States Government or any agency thereof. The views and opinions of authors expressed herein do not necessarlly state or reflect those of the United States Government or any agency thereof. 


\section{DISCLAIMER}

Portions of this document may be illegible in electronic image products. Images are produced from the best available original document. 
This report was prepared as an account of Government sponsored work. Neither the United States, nor the Commission, nor any person acting on behalf of the Commission:

A. Makes any warranty or representation, expressed or implied, with respect to the accuracy, completeness, or usefulness of the information contained in this report, or that the use of any information, apparatus, method, or process disclosed in this report may not infringe privately owned rights: or

B. Assumes any liabilities with respect to the use of, or for damages resulting from the use of any information, apparatus, method, or process disclosed in this report.

As used in the above, "person acting on behalf of the Commisston" includes any employee or contractor of the Commission, or employee of such contractor, to the extent that such employee or contractor of the Commission, or employee of such contractor prepares, disseminates, or provides access to, any information pursuant to his employment or contract with the Commission, or his employment with such contractor.

\section{ALCO LEGAL NOTICE}

This report was prepared by Alco Products, Incorporated in the course of work under, or in connection with, Contract No. AT(30-3)-326, issued by U. S. Atomic Energy Commission, New York Operations Office and subject only to the rights of the United States, under the provisions of this contract, Alco Producte, Incorporated makes no warranty or representation, express or implied, and shall have no liability with respect to this report ar any of its contents or with respect to the use thereof or with respect to whether any such use will infringe the rights of others. 


\section{DISTRIBUTION}

COPIES

$1-3$

4-6

7

6

9

$10-11$
New York Operations Office

$U_{\text {s }} S_{\text {, Atomic Energy Commission }}$

376 Hudson Street

New York 14, New York

Attention: Chief, Army Reactors Branch, NYOO

U. S. Atomic Energy Commission

Army Reactors Branch

Division of Reactor Development

Washington 25, D. C.

Attention: Chief, Water Systems Profect Branch Office, Ass't. Director (Army Reactors)

U. S. Atomic Energy Commission

Chief, Patents Branch

Washington 25, D. C.

Attention: Roland A, Anderson

U. S. Atomic Energy Commission

Chief, New York Patent Group

Brookhaven National Laboratory

Upton, New York

Attention: Harman Potter

Chief of Evaluation Planning Branch

Civilian Reactors

U. S. Atomic Energy Commission

Washington 25, D. C.

Nuclear Power Field Office

USERDL

Fort Belvoir, Virginia

Attention: Chief, Nuclear Power Field Office 
Union Carbide Nuclear Corporation

Oak Ridge National Laboratory

Y-12 Building 9704-1

P. O. Box "Y"

Oak Ridge, Tennessee

Attention: A. L. Boch

14

U. S. Atomic Energy Commission

Reference Branch

Technical Infor mation Services Extension

P. O. BOX 62

Oak Ridge, Tennessee

15-16

Sylvania Corning Nuclear Corporation

Bayside, Long Island,

New York

Attention: Mr. L. Smiley

$17-18$

Metals \& Control

Nuclear Diviston

Attleboro, Massachusetts

Attention: Mr. J. Williams

$19-20$

General Electric Company

San Jose, California

Attention: Mr. G, E. Richards

$B$ Colvin Avenue

Albany 1, New York

21-22

National Lead Company

Nuclear Power Division

Albany, New York

Attention: Mr. J, Farr

$23-24$

D, E. Makepeace Company

Division of Union Plate \& Wire Company

Attelboro, Massachusetts

Attention: Mr. J. H. Durant 


\section{DISTRIBUTION (Cont'd)}

COPIES

25-26

Curtiss-Wright Corporation

Quehanna, Pennsylvania

Attention: Mr. C. Leyse

$27-28$

Martin Company

Nuclear Division

Baltimore, Maryland

Attention: Mr. F. J. Perella

$29-30$

Combustion Engineering, Incorporated

Prospect Hill Road

Windsor, Connecticut

Attention: Mr. A. F, Miller

31-32

Westinghouse Electric Company

19 Railroad Avenue

Albany, New York

Attention: Mr. R. Purdy

33-34

Olin-Mattheson Corporation

New Haven, Connecticut

Attention: Mr D. Seth

Battelle Memorial Institute 505 King Avenue

Columbus, Ohio

Attention: S. Paprocki

Dr. R. L. Murray

North Carolina State College

P. O. Box 5596

State College Station

Raleigh, North Carolina

E. B. Gunyou

D. D. Foley

R. D. Robertson

A. Marimpietri

R. A. Shaw

E. C. Edgar

R. Kellerman

A. Wilder

File 
FOREWORD . ........................ 1

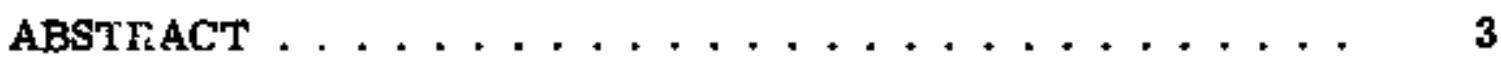

I. ABSORBERS SECTION SPECIFICATIONS .......... 5

A. Core Material Requirements .............. 5

B. Material Specification . . . . . . . . . . . . 5

1. Absorber - Neutron............... 5

2. Matrix Material ................ 5

3. Diffusion Barrier Foil .............. . 6

4. Wrought Stainless Steel . . . .......... 6

c. Dimensional Requirements .............. 8

D. Finist Requirements .................

E. Qualification of Absorber Plate Fabrication

Procedures ................... 9

1. Introduction ................. 9

2. Method of Qualification .............. 9

3. Preparation of Qualification Samples. . . . . . . 9

4. Tests for Qualification ............... 9

a. Visual Inspection ................ 9

b. Radiographic Examination ........... 10

c. Surface Contamination ........... 10

d. Homogeneity ............... 10 
TABLE OF CONTENTS (CONT'D)

Page

4. Tests for Qualification (Cont'd)

e. Bond Integrity ............... 10

f. Clad-Core-Clad-Thickness .......... 10

g. End Condition . . . . . . . . . . . 10

h. Fragmentation and Stringering. ........ 11

5. Conformance of Fabrication Procedures . . . . . . 11

F. Qualification of Procedures for Fabrication of

Absorber Section . . . . . . . . . . . . . . 12

1, Introduction ................... 12

2. Method of Qualification ............. 12

3. Preparation of Qualification Sample ......... 12

4. Tests for Qualification ............... 12

a. Visual Inspection . . . . . . . . . . . . 12

b. Weld Integrity ............... 13

5. Conformance of Fabrication Procedure ........ 13

G. Liatson and Inspection . . . . . . . . . . . . 13

H. Certification ................... 14

I. MANUFACTURING PROCEDURES. . . . . . . . . . 15

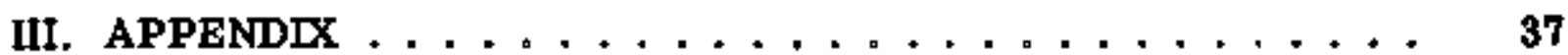

IV, DRAWINGS ....................... 47

vitt

$$
\text { Sis }-94
$$




\section{LIST OF ILLUSTRATIONS AND DRAWINGS}

Page

Fig. 1 Photomicrograph of Typical Europium Oxide Core . . . . . 11

Fig. 2 Furnace Assembly for High Firing Europium Oxide . . . . 17

Rare-Earth Powder Metallurgy Core Order Form . . . . . . . . . . 39

Rare-Earth Powder Metallurgy Core Order Forn . . . . . . . . . 40

Rare-Earth Powder Metallurgy Core Order Form . . . . . . . . . 41

Powder Metallurgy Fabrication Form ... . . . . . . . 42

Absorber Plate Fabrication Record. . . . . . . . . . 43

Radiographic Inspection Sheet. . . . . . . . . . . . . . . 44 44

Absorber Section Assembly and Inspection Sheet. . . . . . . . . 45

Drawings

D9-13-2094-B...................... 49

D9-13-2092-B......................... 51

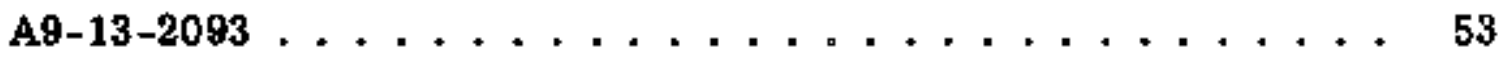

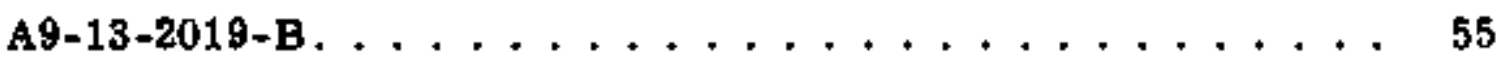


FOREWORD

These specifications were prepared to aid in the procurement of the Control Rod Absorber Section for Core II of PM-2A from an industrial manufacturer.

The material contained herein is hased on ORNL-2733 and incorporates changes which are the result of design and material changes in addition to process changes resulting from experience gained during the manufacture of similar components by a commercial fabricator. 
WAS INTENTIONAIIY LEET BLANK 


\section{ABSTRACT}

The control rod absorber section consists of composite plates joined by welding to form a rectangular parallelepiped. The composite plates consist of compacts of europium oxide in a stainless steel matrix that are clad with stainless steel by hot roll-bonding.

These specifications cover materials and process required to produce the absorber sections. The procedural specifications are spectfic for manufacturing these components, and represent a detailed guide for fabricators. It is recognized that because of differences in equipment, fabricators may be required to motify some of the detalled procedures to arrive at the same result. Prior approval for any deviation from these specifications must be approved by the Contracting Agency, or its authortzed representative. 


\section{ABSORBER SECTION SPECIFICATIONS}

A. Core Materiál Requirements.

1. Neutron Absorber

Europium content per plate, $g$

151.00

Allowable tolerances*

Weighing

Europium oxide

Handling losses

$\pm 0.3 \%$

$\pm 0.5 \%$

$-0.1 \%$

2. Matrix Material

Staintess steel powder (prepared from

elementals) makeup, per plate

Iron, $\mathrm{g}$

220.95

Chromium, B

56.01

Nickel, g

Allowable tolerances*

Weighing

Handling loss

B. Material Specifications

1. Neutron Absorber

The neutron absorbing material shall be a thoria-free high-purity europium oxide containing a nominal $98 \mathrm{wt} . \%$ europium oxide. Received europium oxdde, "dead-burned" from the oxalate, shall be high fired in a tungsten crucible under a dry hydrogen atmosphere for 3 hours at $3090^{\circ} \mathrm{F}$. After firing, the material shall be comminuted to a particle size of less than $44 \mu$ by hammer forging and intermediate screening to avoid excesstve fines. This material should contain a minimum of 85 wt $\%$ europium. the thoria

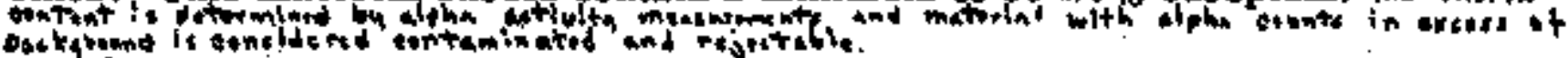

2. Matrix Material

: The matrix material and diffusion barrier foil material shall be prepared from elemental iron, chromium and nickel powders in the weight ratio of 71,18 and 11 , respectively. The particle size of all materials

* Allowable tolerances were established by ORNL as a result of uncertainties involved in fabricating absorber sections for Core II of SM-1. 
is $\mathbf{- 3 2 5}$ mesh. The iron powder should be hydrogen annealed electrolytic iron with a minimum iron content of $99.0 \mathrm{w} / \mathrm{o}$. The nickel powder shall be prepared by the carbonyl process and the chromium powder may be produced either electrolytically or by lithium reduction. The maximum content of impurities for each element is as follows:

$\begin{array}{llll}\text { Siltcon } & 0.03 \mathrm{w} / \mathrm{o} & \text { Cadmium } & 0.002 \mathrm{w} / \mathrm{o} \\ \text { Oxygen } & 0.10 \mathrm{w} / \mathrm{o} & \text { Boron } & 0.002 \mathrm{w} / \mathrm{o} \\ \text { Carbon } & 0.02 \mathrm{w} / \mathrm{o} & \text { Rare Earth's } & 0.002 \mathrm{w} / \mathrm{o}\end{array}$

3. Diffusion Barrier Foil

The foil is prepared by blending, pressing, sintering, rolling, and annealing the above matrix material. The foil is rolled to a thickness of $0.005^{\prime \prime} \pm 0.0005 "$.

\section{Wrought Stainless Steel}

This specification covers a high quality stainless steel to be furnished in the form of sheared mill plate or sheet.

This steel is AISI Type 347 having the chemistry limits set forth in ASTM A-240-58T except that the cobalt shall be 0.025 max. w/o and tahtadum shall be 0.01 max.

Chemical Composition: - in w/o

\begin{tabular}{|c|c|c|}
\hline Element & ASTM Specification & Specification \\
\hline $\begin{array}{l}\text { Carbon } \\
\text { Nickel } \\
\text { Chromium } \\
\text { Manganese } \\
\text { Phosphorous } \\
\text { Sulfur } \\
\text { Silticon } \\
\text { Columbium + Tantalum } \\
\text { Cobalt } \\
\text { Tantalum } \\
\text { Nitrogen } \\
\text { Molybdenum } \\
\text { Copper }\end{array}$ & $\begin{array}{l}0.08 \text { max. } \\
9.00-13.00 \\
17.00-19.00 \\
2.0 \mathrm{max} . \\
0.045 \mathrm{max} . \\
0.030 \mathrm{max} . \\
1.0 \mathrm{max} . \\
10 \times \mathrm{C} \min ; 1.10 \mathrm{max} . \\
-2 . \\
0.05 \max . \\
0.50 \mathrm{max} . \\
0.50 \max .\end{array}$ & $\begin{array}{c}0.06 \max . \\
9.25-9.75 \\
18.00-18.75 \\
1.00-1.50 \\
0.030 \max . \\
0.030 \max . \\
0.50-0.60 \\
0.60-0.80 \\
0.025 \max . \\
0.01 \text { max. } \\
0.04 \max . \\
0.20 \max . \\
0.20 \max .\end{array}$ \\
\hline 309 & & \\
\hline
\end{tabular}


The material with the above composition limits will be used for inert gas shielded tungsten arc welding without filler metal. In addition to meeting the chemical restrictions set forth in this specification, the delta ferrite content of this material, as calculated from the Schaeffler Constitution Diagram shall be a minimum of $2 \%$ and a maximum of $10 \%$.

In calculating the delta ferrite content from the Schaeffler Constitution Diagram, the following multiplying factors shall be used in computing the chromium and nickel equivalents for the production order:-

\begin{tabular}{lc} 
Element & Factor \\
\cline { 2 - 2 } Carbon & 30 \\
Manganese & $1 / 2$ \\
Silicon & $1-1 / 2$ \\
Chromium & 1 \\
Nickel & 1 \\
Cb + Ta & $1 / 2$ \\
Nitrogen & 30 \\
Copper & 2 \\
Molybdenum & 1
\end{tabular}

In the event that the chemistry of the heat is outside the range of the desired specification, but within the ASTM chemistry, and contains a delta ferrite content in the range of 2 to $10 \%$ as calculated from the Schaeffler Diagram, the heat will be acceptable.

In the event the chemistry is outside the desired specification limits, and below the lower limit of $2 \%$ delta ferrite, a weldability test shall be made without filler addition. Freedom from cracking shall conside $r$ the heat acceptable. The type and details of the welding test shall be as mutually agreed upon between Allegheny Ludlum and Alco Products, Inc. Material that is not weldable, as determined by this test will not be acceptable.

Inclusion Content:-

The inclusion content of this material in the form of 1 "thick sheet bar as deter mined by Method " $B$ " set forth in ASTM 'E-45-51 shall be equal to or better than an inclusion rating of $\left(12-5^{12}\right)$. This rating as determined by method " $\mathrm{B}$ " shall be comparable to the following method " $\mathrm{A}$ " rating:-

Inclusion Type

Type A (Sulfide)

Type B (Alumina)

Type C (Silicate)

Type D (Globular Oxide)
Thin Series

2

$2-1 / 2$

3

3

Heavy Serles

1-1/2

2

$3-1 / 2$

2 
The thickness of the inclusions found in 1" thick sheet bar shall not be any greater than that specified in the Inclusion Chart of ASTM E-45-51 specification.

Physical Properties:-

\begin{tabular}{|c|c|c|}
\hline Tensile Strength & $\begin{array}{l}0.2 \% \text { Off set } \\
\text { Yield Strength }\end{array}$ & $\begin{array}{l}\text { \% Elongation } \\
\text { in 2" }\end{array}$ \\
\hline 75,000 psi & 30,000 psi & $40 \%$ \\
\hline
\end{tabular}

Purchase Condition:-

Cold rolled, annealed, and pickled sheared mill plate or sheet.

C. Dimensional Requirements

The component parts shall be manufactured and assembled in accordance with the dimensional specifications set forth on Alco Drawings listed below:

PM-2A Neutron Absorber Section

Description of Item

Absorber Plates

Pin

Absorber Section Assembly
Reference Drawing

Alco Drawing D9-13-2092-B

Alco Drawing A9-13-2093

Alco Drawing A9-13-2019-B

Alco Drawing D9-13-2094-B

Since these drawings are subject to revision, it is advisable that potential fabricators contact the Contracting Agency, or its authorized represen = tative, in order to obtain the latest prints before initiating any fabrication work.

D. Finish Requirements

All machined surfaces in contact with the coolant shall have a finish of at least 125 RMS except as noted in the drawings. 


\section{E. Qualification of Absorber Plate Fabrication Procedure}

\section{Introduction}

Quality control of the absorber section is primarily attained by rigid adherence to proven fabrication procedures. Thus, specifications for the absorber sections cannot be prepared along the lines normally used for industrial products, in which quality is assured by nondestructive inspection to industry -wide standards. Consequently, the manufacturer will be required to qualify the fabrication procedure which is to be employed in production.

\section{Method of Qualification}

Qualification shall be performed by subjecting three sample plates to the tests outlined in 4-a through 4-i of this section. Approval of qualification shall be given by the Contracting Agency, or its authorized representative when it has been demonstrated to the satisfaction of the Contracting Agency, or its authortzed representative that the requitrements of 4-a through 4-h have been met.

\section{Preparation of Qualification Samples}

The three sample plates shall be prepared in conformance with the exact and complete fabrication procedure which is proposed to be used in the manufacture of the absorber sections. Europium oxide, identical in every respect with the material to be used in the absorber sections, shall be used in the sample plates. The sample plates shall be subjected to the identical hightemperature treatment which will be encountered in the proposed procedure for fabrication of the composite plate. Approval of qualification must be obtalned prior to inception of the manufacture of absorber plates unless otherwise specifically authorized by the Contracting Agency, or its authorized representative. Approval by the Contracting Agency, or its authorized representative of the procedure as used in establishing qualification or of any modification thereof will not relieve the manufacturer of any responsibility for any phase of the fabrication of the absorber section or for conformity to specification requirements.

\section{Tests for Qualification}

a. Visual Inspection - The three sample plates shall be inspected for over-all width, length, and thickness dimensions and shall be inspected for pitting, surface condition, and finish. The three sample plates shall meet all dimensional requirements and shall not exhibit any oxide indentations or pits in excess of 0.005 in. deep, scratches over 0.002 in. deep, blisters, scale, or dents. 
b. Radiographic Examination - The three sample plates shall then be radiographed to delineate the europium oxide bearing core area and voids or other internal defects. The radiographs shall be made using proper techniques with a fine-grained film such as Eastman " $M$ ". The radiographs shall be used as the basis of measuring core length; core width, and inactlve edges and ends.

The samples shall meet all dimensional requirements and shall exhibit no evidence of voids or other internal defects.

c. Surface Contamination - The three sample absorber plates will be subjected to an alpha count to determine if any possible surface contamination exists. The plate shall be checked for alpha contamination by means of gas flow proportional counting or a similar method. Alpha contamination equivalent to 0.5 micrograms of $U-235$ per square foot shall be the maximum allowable level of contamination. It ts assumed that one microgram of U-235 per square foot is equivalent to 150 disintegrations per minute per square foot of plate surface.

d. Homogeneity - Two of the three sample plates shall be examined for homogeneity. Five miniature samples of full-plate thickness, approximately one square inch in area, shall be extracted from each of the two plates on a diagonal between core corners and approximately equally spaced beginning 2 inches from core-end and 1/4 inch from core-edge interfaces. These samples shall be dissolved and chemically analyzed for total europium content, and the results expressed on a weight percent basis. For each of the two plates; variation from location to location shall not exceed $5 \%$ of the nominal europium content.

e. Bond Integrity - Five transverse samples, equally spaced along the plate length, and three longitudinal samples from each end, equally spaced across the width, stall be removed from one of the three sample plates. After proper preparation and electrolytic etching with $5 \%$ chromic acid reagent, the samples shall show no evidence, of lack of bond at the clad-frame interface or at the clad-core ard frame-core intèrfaces upon metallogiraphic examination at 100 diameters.

f. Clad-Core-Clad Thickness - The five transverse samples used in " $e$ " shall be measured to determine clad-coré-clad thickness. As measured by calibrated eye-piece, the thickness at all points shall show compliance with specified thicknesses.

g. End Conditions - The six longitudinal samples used in " $\mathrm{e}^{\text {t" }}$ sholl be : examined metallographically. These samples shall show 
no evidence of the presence of core material in the inactive portions as dimensionally specified.

h. Fragmentation and Stringering - One longitudinal sample at least one-half inch long shall be taken from the core of two of the plates. When examined metallographically, none of these samples shall exhibit fragmentation and stringering greater than that illustrated in Figure 1. The europium oxide shall exhibit no evidence of reaction with matrix, clad or frame material at magnifications up to $1500 \mathrm{X}$.

ORNL Y-28331

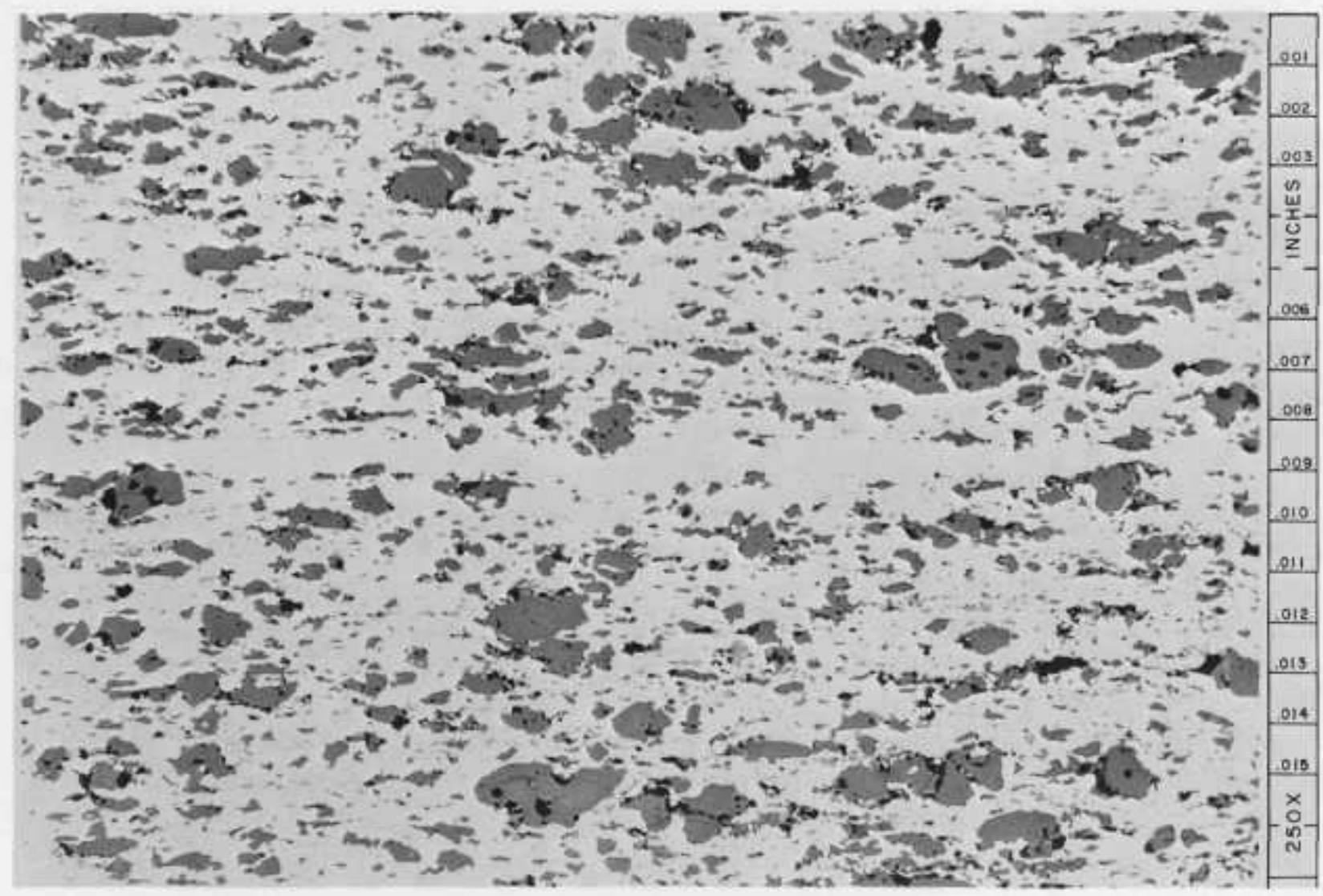

Figure 1. Typical Microstructure of Fabricated Absorber Plate Containing $36 \mathrm{w} / \mathrm{o}$ Europium Oxide in Stainless Steel. (As polished 250X.)

\section{Conformance of Fabrication Procedure}

The exact procedure used in fabricating the sample plates and which is finally proposed to be used in fabricating the absorber plates shall be furnished to the Contracting Agency, or its authorized representative at the 
conclusion of fabrication of qualification plates and at least one week in advance of the request for approval of qualification. Unless otherwise specifically authorized in writing by the Contracting Agency, or its authorized representative, the procedure used in fabricating the sample plates shall be strictly adhered to in fabricating the final plates and the absorber sections.

F. Qualification of Procedures for Fabrication of Absorber Section

1. Introduction

In addition to the qualification procedures for fabricating absorber plates, the manufacturer is required to qualify the operator and the procedure to be employed in welding the absorber sections.

\section{Method of Qualification}

Qualification shall be performed by subjecting one assembledandwelded solid stainless steel absorber section to the tests outlined in Section E, item 4. Approval of qualification shall be given by the Contracting Agency, or its authorized representative when it is demonstrated to the satisfaction of the Contracting Agency, or its representative that the requirements have been met.

\section{Preparation of Qualification Sample}

The simulated absorber shall be prepared in conformance with the exact and complete assembly procedure which is proposed to be used in the manufacture of the absorber sections. Solid stainless plates of specified dimensions are to be used in the qualification section. Approval of qualification must be obtained prior to inception of manufacturing of the absorber sections from the Contracting Agency, or its authorized representative. Approval by the Contracting Agency or its authorized representative of the procedure used in establishing qualification or of any modification thereof will not relieve the manufacturer of any responsibility for any phase of the fabrication of the absorber section or for conformity to specification requirements.

\section{Test for Qualification}

a. Visual Inspection - The welded test section shall be inspected for over-all cross-sectional width and length dimensions and for weld integrity. The test section shall meet all dimensional requirements. The welds shall be in accordance with good commercial practice. The bead shall be continuous and limited to an area .050 to .200 in. measured from the outside edge of the absorber. 
The finished test sectlon must pass through a final test box with internal dimensions $2.650 \times 2.650 \times 26-1 / 16$ in. without binding at any point. Any binding of the test section in the test box is cause for rejection.

b. Weld Integrity - Four transverse sections, equally spaced along the length of the finished test section shall be removed and examined metallographically for weld penetration. The weld bead shall be essentially flush with the plate surface. The average depth of penetration should be .025 in. A penetration of less than 0.015 in. as measured from the plate surface by a filar micrometer is cause for rejection. The welds shall be essentially free of porosity, inclustons, and tungsten partícles.

\section{Conformance of Fabrication Procedure}

These specifications cover materials and processes required to produce completed elements. The procedural specifications are specific for manufacturing these components at ORNL and other facilities, and represent a detailed guide for fabricators. It ts recognized that because of differences in equipment, fabricators may be required to modify some of the detailed procedures to arrive at the same result. Prior approval for any deviation from these specifications must be approved by the Contracting Agency or its authorized representative.

Delivery of an acceptable product, including materials, dimensions, loading, and all other requirements, remains the responsibility of the manufacturer.

The exact procedure used in fabricating the test section and which in to be used in fabricating the final absorber sections shall be furnished to the Contracting Agency, or its authorized representative at the conclusion of fabrication of the qualification section and at least one week in advance of the request for approval of qualification. Unless otherwise specifically authorized in writing by the Contracting Agency, or its authorized representative the procedure used in fabricating the test section shall be strictly adhered to in fabrtcating the final assemblies.

\section{G. Lialson and Inspection}

Free entry shall be given to the Contracting Agency, or its authorized representative to all areas of the manufacturer's plant at any time during the term of the contract for fabricating the absorber sections. The manufacturer shall provide all reasonable assistance, facilities, and co-operation to the 
Contracting Agency, or tts authorized representative for determination of compliance with specificatipns or procedure requirements or for lnspection purposes as may be required.

The Contracting Agency, or its authorized representative will maintain liaison with the manufacturer for the duration of the contract for the following purposes: (1) to provide necessary and reasonable technical assistance as may be required, and (2) to inspect for compliance to the specifications and the approved fabrication procedure. The Contracting Agency, or its authorized representative shall have the right at any time during the term of the contract to reject any and all pieces, parts, components, and products which do not meet the requirements of the spectficatipns, or which have not been fabricated in accordance with the approved procedure, or which fail in any way to meet any of the requirements set forth in this document. Such inspection shall not relieve the manufacturer of any responstbility in any phase of absorber section fabrication or furnishing therepf.

\section{H. Certification}

Certification shall be furnished to the Contracting Agency, or its authorized representative that all materials used in the fabrication and furnishing of the absorber sections are in accordance with the requirements of these spectfications. 


\section{MANUFACTURING PROCEDURES}

\section{A. Introduction}

The essential operations required in processing the absorber sections are: (1) preparation of the europium oxide, (2) weighing and blending of the compact powders for each absorber subcore, (3) pressing, sintering, and coining into a compact of the required dimensions, (4) assembling of the absorber billet constituents, (5) welding and evacuating the billet, (6) cladding by hot roll bonding, (7) descaling of the hot-rolled plate, (B) flatten annealing, (9) marking and shearing of the composite, (10) machining to final length and width dimensions, (11) assembling and welding of the section, (12) attachment of the handle, (13) cleaning of the weld surfaces, and (14) inspection. After the final inspection, the units are degreased and packaged for shipment to the reactor site. These general procedures and the more specific details, which will be described later, represent methods developed and adopted by the Oak Ridge National Laboratory for manufacturing stainless steel-europitum oxide absorber sections for service in Core II. It is recognized that, because of differences in equipment, other fabricators may be required to modify some of the detailed procedures to arrive at an equivalent finished product.

\section{B. Records}

During processing, positive identification of each absorber plate must be maintained along with appropriate data in order to ensure: (1) proper process control, (2) quality control, (3) metallurgical history record, and (4) removal of rejected material. Records of the following items are maintained and copies furnished to the Contracting Agency or its authorized representative with the finished absorber sections: (1) identification of each lot of prefired europium oxide, (2) master log containing materials make-up data and the detailed processing schedule employed in the manufacturing of each plate (to serve as a guide, the forms of the pertinent records are included in the Appendix) and (3) absorber sectton inspection record of critical dimensions.

\section{Europium Oxide Preparation}

Europium oxide obtained from various vendors is normally of low density with extremely fine particle sizes. Such material is not readily suitable for a powder metallurgical dispersoid. Prior to incorporating the oxide in a stainless steel matrix the material is conditioned by a high-firing process. The various stages of this operation are as follows: (1) inspection of the received oxide, (2) pressing, (3) firing, and (4) crushing. 


\section{Inspection of Received Europium Oxide}

It is recommended for optimum conditioning properties that the received oxtde be obtained in a "dead burnt" form from the oxalate with no additional intermediate temperature treatments. Each batch of received oxide is inspected for total europium oxide and thoria content. The material should contain a minimum of $98 \%$ europium oxide.

\section{Pressing}

Prior to high firing, the received powder is pressed into small cylindrical pellets to factiltate powder handling. Approximately $35 \mathrm{~g}$ of the material measured by a $10 \mathrm{cc}$ stalnless steel beaker is pressed into an individual pellet. The measured amount of oxide is poured into the cavity of a double-acting, 0.8 in. diameter powder metallurgy die, leveled, and pressed into pellet form by applying a pressure of about $4 \mathrm{ton} / \mathrm{in} .2$. The resulting pellets are of sufficient strength for handling and have dimensions 0.8 in. diameter by 0.8 in. length.

\section{Firing}

Approximately 10 pellets weighing between $300-350 \mathrm{~g}$ comprise the firing batch size. The individual pellets are placed in a tungsten crucible approximately $2 \times 2 \times 7 \mathrm{in}$. in size which is constructed by edge welding $1 / 8$ in. sheet stock. The loaded tungsten crucible is inserted in a reactor grade graphite crucible mounted in the center of an induction coll. Amorphous thermatomic carbon powder is packed between the reactor grade graphite crucible and the outer quartz furnace tube to serve as an insulator. A reactor grade graphite block $w$ ith an attached off-gassing stem is placed over the reactor grade graphite crucible to prevent the thermatomic graphite from contaminating the europtum oxide pellets. The remainder of the quartz tube is then flled with amorphous thermatomic carbon powder and finally capped with a gas-tight, brass end-plug. A hydrogen gas stem is attached to the lid to permit passage of hydrogen to the pellets during the firing operation. The exit hydrogen gas escapes through the stem attached to the top of the graphite cructble. The pellet firing is carried out at $3090^{\circ} \mathrm{F}$ for a period of three hours. They hydrogen atmosphere gas is a dried hydrogen gas with a dewpoint of at least $-60^{\circ} \mathrm{F}$. The power is varied initially to control the rate of temperature rise in the furnace; a rate of $570^{\circ} \mathrm{F} / \mathrm{hr}$ is average. Temperature measurements are made on the surface of the pellets by sighting an optical pyrometer through the off-gassing stem. Upon completion of the firing, the power is shut off and the furnace air cooled to approximately $300^{\circ} \mathrm{F}$ at which time it is disassembled and the fired pellets removed.

$$
5699
$$




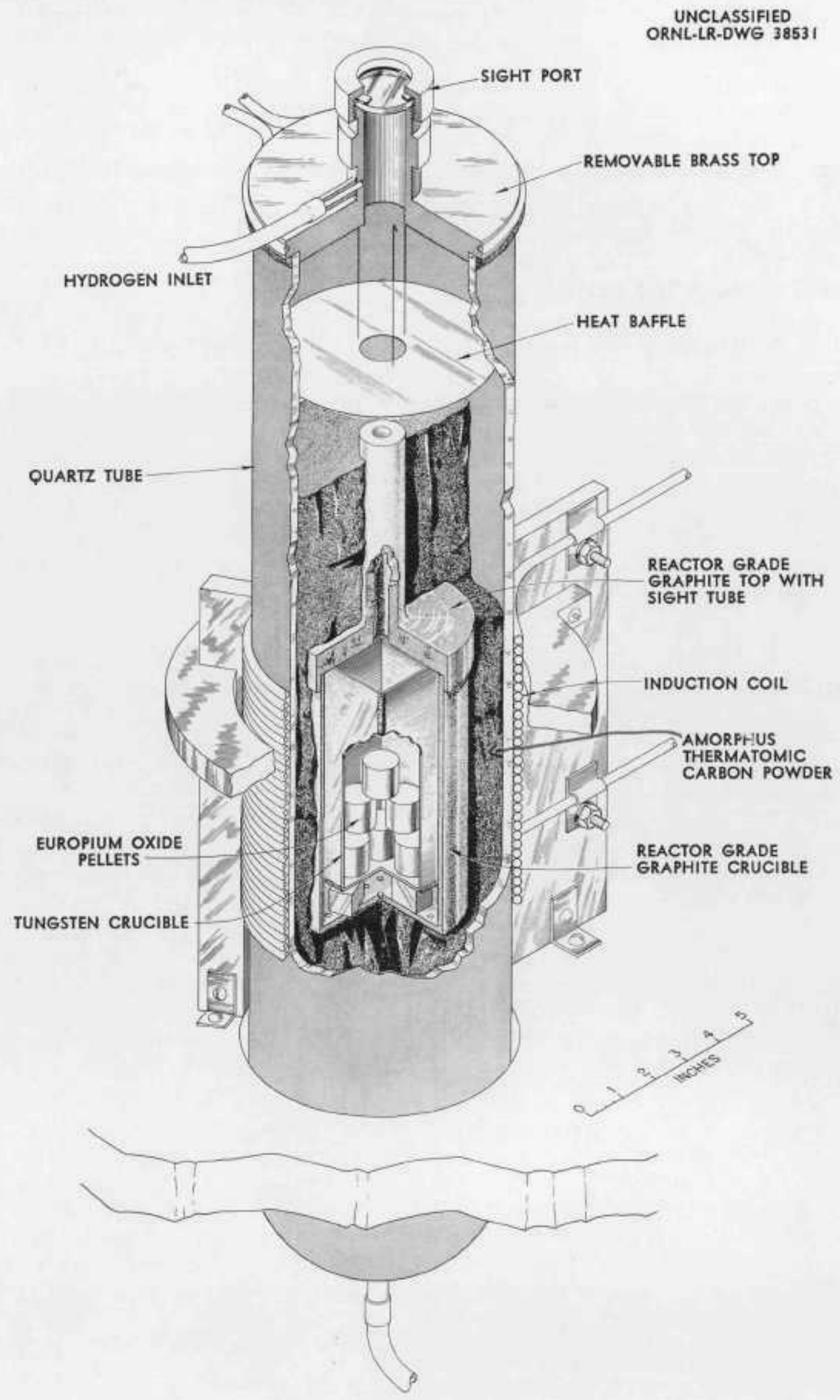

Fig. 2. Furnace Assembly for High-Firing Europium Oxide Pellets. 


\section{Crushing}

The fired pellets are crushed to $\mathbf{- 3 2 5}$ mesh size in a mortar and pestle using a series of intermediate screening operations. Initially one-third of the fired batch size is placed in a mortar and crushed using only impacttype strokes. Clrcular grinding motions were found to produce considerable fines in the crushed oxide. After the pellets have been initially broken down, the product is placed in a series of vibrating screens which separate out the $+100,-100+270,-270+325$, and -325 mesh fractions. Each fraction is then recrushed until the entire material is of a -325 mesh size. The various gizing separations are necessary to minimize presence of fines. The final product from each batch is examined macroscopically to determine if the particles are irregular and not rounded. Since the percentage of europium generally varies in high firing, a representative sample of each batch of hi-fired oxide is analyzed by wet chemistry for total europium content expressed in weight percent.

A spectmen from each processed lot or batch of europium oxide shall be tested for weight change by firing in a dry hydrogen (dewpoint at least $-600 \mathrm{~F}$ ) atmosphere for $1-1 / 2$ hours at $2250 \pm 25 \mathrm{OF}$. The specimen shall be cold pressed in a 1/4 inch diameter die at a pressure of 3100 PSI before firing. The pellet is fired on a molybdenumlined type 316 stainless steel boat in a leak tight inconel muffle. Any weight gain or a weight loss in excess of $0.008 \mathrm{gms}$ will be cause for rejection of the lot or batch of eu- $1,500 \mathrm{qms}$
ropium oxide which this specimen represents. The specimen shall weigh ; $0.010 \mathrm{gm}$ sefore firing.

After high firing the europium oxide must be shipped, stored and handled under conditions which preclude the pickup of any moisture.

\section{Absorber Core Manufacturing}

\section{Calculations}

The neutron absorber and matrix powders are specified in terms of europium and stainless steel. Since the poison used is in the form of a complex europium oxide, it is necessary to determine by calculation the quantity of this material to be incorporated into each core. Each batch of hi-fired europium oxide is assayed for total europium content. Since elemental powders are employed as the matrix material, the quantity of each constituent must be determined by calculation.

Sample calculations lllustrating the method utilized in determining the quantities of europium oxide and matrix powders required in the make-up of each absorber core are listed below:

$$
\text { U. }+21
$$


(a) Data Required

Wt. $\%$ Eu in europium oxide

85 average value

Grams of Eu per plate

151

Wt. $\%$ Fe in matrix steel

71

wt. $\%$ Ni in matrix steel

11

Wt. $\%$ Cr in matrix steel

18

Dimenstons of absorber core

in finished plate

$20.75 \times 2.213 \times 0.090$ in.

Densification of core in finished plate

0.957

(b) Determination of Grams of europium oxide per plate:

$151 \mathrm{~g}$ of Eu X 1.00

$85 \%$ of $\mathrm{Eu}$ in europium oxide $=-177.65 \mathrm{~g}$

(c) Determination of Grams of Matrix Stainless Steel per'Plate

(1) Required core volume in finished plate:

$20.75 \times 2.213 \times 0.090 \times 16.38=67.69 \mathrm{~cm}^{3}$

(2) Volume of core occupied by wrought stainless steel foils*:

$2.103 \times 2.275 \times 0.005 \times 4 \times 16.38=1.57 \mathrm{~cm}^{3}$

* Values based on initial core dimensions.

(3) Core volume occupied by -europium oxide beartng dispersion:

$67.69 \mathrm{~cm}^{3}-1.57 \mathrm{~cm}^{3}=66.12 \mathrm{~cm}^{3}$

(4) Volume occupied by dispersion materials initially:

$66.12 \mathrm{~cm}^{3} \times 0.957$ (densification) $=63.28 \mathrm{~cm}^{3}$ 
(5) Material volume occupied by europium oxide based on europium oxide density of $7.4 \mathrm{~g} / \mathrm{cm}^{3}$ :

$$
\frac{177.65 \mathrm{~g}}{7.4 \mathrm{~g} / \mathrm{cm}^{3}}=24.01 \mathrm{~cm}^{3}
$$

(6) Material volume occupied by matrix steel:

$$
63.28 \mathrm{~cm}^{3}-24.01 \mathrm{~cm}^{3}=39.27 \mathrm{~cm}^{3}
$$

(7) Determination of grams of matrix steel per plate based on

stainless steel $=7.9 \mathrm{~g} / \mathrm{cm}^{3}$

$$
39.27 \mathrm{~cm}^{3} \times 7.9 \mathrm{~g} / \mathrm{cm}^{3}=310.23 \mathrm{~g}
$$

(8) Determination of grams of matrix steel constituents per plate:

(a) Fe -71 wt. $\%$

$$
310.23 \mathrm{~g} \times 0.71=220.26 \mathrm{~g}
$$

(b) Ni - 11 wt. $\%$

$$
310.23 \mathrm{~g} \times 0.11=34.13 \mathrm{~g}
$$

(c) $\mathrm{Cr}-18$ wt. $\%$

$$
310.23 \times 0.18=55.84 \mathrm{~g}
$$

(9) Determination of total grams of core constituents per plate:

$$
177.65+220.26+34.13+55.84=487.88 \mathrm{~g}
$$

(10) Determination of weight percent europium oxide per plate:

$$
\frac{177.65}{487.88} \times 100=36.41 \%
$$

(11) Since each absorber core was manufactured in three parts, the grams of europium oxide per-súb-core are:

$177.65 \mathrm{~g} \mathrm{x} 1 / 3=59.127 \mathrm{~g}$

Likewise the grams of $\mathrm{Fe}, \mathrm{Ni}$, and $\mathrm{Cr}$ in the matrix steel are:

$$
\begin{aligned}
& \mathrm{Fe}-220.26 \times 1 / 3=73.42 \mathrm{~g} \\
& \mathrm{Ni}-34.13 \times 1 / 3=11.38 \mathrm{~g} \\
& \mathrm{Cr}-55.84 \times 1 / 3=18.61 \mathrm{~g}
\end{aligned}
$$


As might be expected, the densification factor $\left(\frac{\text { measured volume }}{\text { theoretical volume }}\right)$ of the fabricated core material has a significant effect on the amount of elemental stainless steel powder required to meet dimensional speciflcations in the finished composite plate. This factor has been determined to be approximately . 96 for the spectfic equipment and processing methods employed at the Oak Ridge National Laboratory. However, any major change in equipment or procedure will probably shift this factor; and under such circumstances, it will be necessary to alter the grams of elemental stainless steel required in the material charge for the absorber compact. Such changes in the total material charge affect the grams of elemental stainless steel powder in the three sub-cores which are stacked in the billet assembly to make up the total core material charge.

\section{Weighing of Component Powders}

The absorber section consists of three compacts or sub-cores stacked on top of each other. The component powders for each sub-core are separately wetghed and then combined in a single blending jar. With the exception of possible losses during subsequent pressing and sintering operations, this method offers accurate accounting and reproducibility of the critical ingredient, europium oxide, in each absorber sub-core and ultimately in each absorber core within the limits of the accuracy of the weighing balance. Europium oxide is the first matertal loaded into the blending jar and is followed by the constituents of the elemental stainless steel powder, namely electrolytic iron, nickel, and chromium. Since the absorber section contains no contaminated or active materials, handling of all powders can be done in a conventional manner. During processing, five jars comprise a batch. The individual weighing procedures are as follows:

\section{(a) Weighing of europium oxide -}

The neutron poison, europium oxide, in the sub-core ts weighed to an accuracy of at least $+0,03$ ron a Grammatic balance of $200 \mathrm{~g}$ capacity. A $4 \times 4$ in. sheet of glazed paper with glazed side up and of known weight is placed on the pan. The europium oxide is added to the paper and accurately weighed. The material is then poured into a clean, dry, wide-mouth, glass jar of 4-ounce capacity. A camel's hair brush is used to brush any remaining particles of europium oxide into the jar, which is then capped.

(b) Weighing of the elemental stainless steel powder -

The elemental stainless steel constituents, electrolytic iron, nickel, and chromium are weighed in exactly the same manner 
as the europium oxide, with the exception that a triple-beam balance is used. The individual powders are weighed to a . tolerance of $\pm 0.01 \%$. After each weighing, the Individual powder is then transferred to a blending jar contaning the previously weighed europium oxide. The jar is immediately recapped. This procedure is again repeated for the two remaining constituents.

These operations are repeated until the lot of five jars has been processed. After final weighing and capping, the joint between the cap and the jar is sealed with masking tape, and each jar identified by europium oxide batch number.

\section{Blending}

The powders are blended to achieve a homogeneous mixture of europium oxide and elemental powders. A modified U.S. Stoneware Company Double Cone Blender, Model 733, is used. The blender cones are replaced by a pair of two-quart steel cans mounted on the motor shaft at an angle of 30 degrees with the vertical. Ten jars or two lots, each containing the specified quantities of europium oxide and elemental powders, are loaded into each can with sufficient padding to prevent breakage of the jars during the blending operation. The cans are rotated at this oblique angle for three hours.

\section{Initial Cold Pressing of the Core Ingredients}

The initial operation in shaping the blended powders into a compact suitable for assembling into an absorber plate billet is to cold press into a "green" compact. A Baldwin press of 150-ton capacity and with a Vickers Hydraulic control system to permit variable movement of the ram is employed for compaction. The press has two rams, an upper fixed ram extending down from the top crosspiece and a lower ram which is movable. On the top of the lower movable ram is fastened a large platen onto which is placed the powder metallurgy die set. The die set consists of a female die which is spring mounted to the movable ram and a die punch and filler block. The bottom of the die punch contacts the movable ram, while the top of the filler block, inserted into the die cavity after the powder, contacts the stationary ram.

After assembly has been completed, a solution of $10 \mathrm{wt}$ C. P. Stearic Acid - 90 wt $\%$ carbon tetrachloride, which serves as a die lubricant for each die charge, is applied with a 1/4 inch camel's hair brush around the top of the die cavity and the lower sides of the filler block. The die face is, occasionally lubricated when the pressed core adheres to it because of wear. The blended powder from each jar is poured into the die cavity. The jar is brushed thoroughly to ensure complete transfer of all powders. Once the 
core material has been loaded into the cavity, it is leveled with the straight edge of a scoopula. The filler.block is inserted into the die and the lower ram then raised until the die insert contacts the stationary ram. The blended powders are initially pressed at 10 tsi pressure (approximately 45 -tons total load) for 15 seconds to a thickness of approximately 0,404 in. The filler block is' removed and the "green" compact ejected by elevating the die punch with the hand lever. Extreme care must be exercised in removing the "green" compact to avoid breakage since the compact is of low strength and density. The pressed compact is then carefully placed on the sintering boat to minimize handling.

\section{Initial Sintering of "Green" Compacts}

The sintering operation is carried out in a General Electric 20-kw laboratory molybdenum-wound furnace equipped with a 3 in. diameter Inconel muffle. Thirty-six inches of the muffle extends beyond the furnace and acts as a cooling chamber. The sintering temperature is $2250^{\circ} \mathrm{F}$. Uniformity of temperature along the length of the sintering boat is maintained at $\$ 250 \mathrm{~F}$. Dry hydrogen with a dewipoint of $-60^{\circ} \mathrm{F}$, as measured by an Alnor Dewpointer at the gas inlet, is used as atmosphere in the muffle. Hydrogen flow required for this size muffle is approximately $20 \mathrm{cfh}$ under steady-state conditions, al though the gas flow is increased when the muffle door is opened during insertion or removal of compacts. The sintered compacts do not exhibit any evidence of axide formation.

The sintering boat which contains the pressed "green" compacts is constructed of type $\mathbf{\$ 1 6}$ stainless steel formed into the shape of an " $\mathrm{H} "$ ". The crossbar between the two vertical sides is 2-1/2 in. wide $\times 14$ in. long, and is located approximately $1 / 2$ in, above the bottom of the legs.

Prior to positioning five "green" compacts end to end along the length of the boat, a molybdenum-foil liner is inserted to prevent the sub-cores from contacting the stainless steel. This liner has 1/16 in. diameter molybdenum wire spacers welded along its length upon which the five compacts rest. This spacer wire is used to permit access of hydrogen gas to all surfaces of the compacts.

The sintering boat containing the five compacts is inserted in the furnace at $2250^{\circ} \mathrm{F}$ and the system purged with hydrogen. The compacts remain in the hot zone for 1-1/4 hours. The boat is moved to the cooling chamber, allowed to cool to $450^{\circ} \mathrm{F}$ under the hydrogen atmosphere, removed from the muffle, . and air cooled to room temperature. Again, in an effort to minimize handing, cores are not removed from the boat until re-inserted into the pressing die for additional compaction. 


\section{Repressing the Sintered Compacts}

The sintered compacts are repressed in the original die set described In Item 4, Section D. The shrinkage encounted during sintering permits re-insertion of the compact into the same die cavity. After careful insertion, the sintered compacts are pressed under a pressure of 31 tst. (ap:proximately 150-ton load) for 15 seconds to improve densification: Therepressed core thickness is approximately 0.339 in: The repressed compacts are ejected from the die, and repositioned on the sintering boat.

\section{Resintering of Compacts}

The repressed compacts are resintered in the furnace described in Item 5 of Section $D$ under dry hydrogen for 1-1/4 hours at 22500 F and cooled in cold leg of muffle to $570^{\circ} \mathrm{F}$. This second sintering promotes densification and alloying of the elemental powders.

\section{Coining of Sintered Compacts}

The shrinkage encountered during the second sintering operation permits re-insertion of the compact into the original die cavity for coining. After careful loading, the resintered compacts are pressed under a pressure of 31 tst: for 15 seconds to obtain the desired dimensions and improved densification. The coined compacts are ejected from the die and transferved to the inspection area. The coined compact thickness is approximately 0.327 in.

\section{In-Process Inspection}

Since it is necessary to control the europium content of the absorber, it is desirable to weigh the compacts prior to the completion of the sub-core processing. Because of uncertain losses due to the reduction of metal oxides by hydrogen during sintering, it is impractical to consider weight losses of the compact after this operation. The handling losses are determined therefore prior to loading the furnace for initial sintering. For convenience, all five sub-cores are wetghed together. If the total permissible deviation for a single core is exceeded by the entire batch, each sub-core must be individually weighed for acceptance or rejection. Deviation from the charged weight greater than spectfied in Section V-A for each core is the basis for rejection. Compacts with obvious chips and flaws, of course, are weighed individually and not included in the batch weighing. After sintering the compacts are examined to determine whether any obvlous chipping or spallation occurred during the required handling. 
Each core is measured with a micrometer after processing to deter mine if the compact meets the thickness requirement of $0.327+0.002 \mathrm{in}$. Length and width dimensions are established by die design.

\section{Core Storage}

Each acceptable lot of cores is wrapped in paper. These packages are marked to identify batch number and europium oxide lot number, and inserted in an ordinary desiccator if storage time is to be less than 48 hours. If a storage time of more than 48 hours is required, a vacuum desiccator is used.

\section{E. Billet Assembly}

\section{Material Preparation}

The billet containing the europium oxide stainless steel dispersion is designed to permit evacuation of the billet inter lor prior to rolling into' a composite plate. The components consist of two wrought stainless steel cover plates; a frame into which the europium oxide compacts are inserted; three sub-cores containing the europium oxide, and ftve stainless steel folls.

a. Stainless Steel Cover Plates - The cover plates are fabricated from 5/16 in. plate (minimum thickness of $0.318 \mathrm{ln}$.) which may require . cold rolling to the specified thickness of $0.320 \mathrm{in} .+0.002$ in. The plates are sheared to $4-3 / 4$ in. $x 4-3 / 4$ in,$+1 / 16$ in. which allows approximately a $3 / 16$ in. Overlap of the cover plate on the frame. Since only very small reductions are necessary during cold rolling, it is recommended practice to shear the received plate to the above dimensions and to reduce to the required thickness by cross-rolling.

b. Picture Frames - Plcture frames are machined from 1-in. plate. Since the billet is to be subsequently evacuated prior to rolling, holes are drilled into the frame to provide a free path for evacuation. It is important that the finished plate be free of potential defects caused by the drilled holes. By the design, in shearing and machining the plate to final size, these regions will be in the scrapped portion of the plate. An entrance hole, $0.225 \mathrm{in}$. In diameter, is drilled in the geometric center of the tail edge of the plate frame to a depth of $3 / 8$ in. A corresponding 0.225 in. diameter hole is drilled through the frame perpendicular to and meeting the end of the first hole to from a " $T$ ".

c. Evacuation Tube - The tube for evacuation of the billet interior is type 304 or 347 stainless steel, with a nominal outside diameter of 0.225 in. an inside diameter of $0.175 \mathrm{in}$, and a length of 12 in.

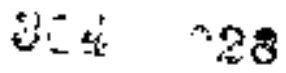


d. Folls - Foils are prepared from electrolytic iron, chromium, and nickel powders, in the weight ratio of $71-18-11$, respectively. The silicon content of each powder is limited to a maximum of $0.03 \mathrm{wt}$. $\%$. The foils serve two purposes: (1) as a bonding aid between the three sub-cores and (2) as a barrier to prevent possible reaction between the europium oxide and the wrought stainless steel. The foils are prepared by blending the specified quantity of each of the elemental powders for 3 hours in an oblique blender; cold pressing at 31 tsi; sintering in dry hydrogen of $-600 \mathrm{~F}$ dewpoint at $2250^{\circ} \mathrm{F}$ for one hour; and colning at 31 tsi. The coined stainless steel is cold rolled on a Bliss 4-high mill to 0.005 in. \pm 0.0005 in. with intermediate one hour anneals at $2250^{\circ} \mathrm{F}$ to mtnimize edge cracking. Light reductions per pass coupled with cross-rolling yield the most satisfactory material.

\section{Assembly and Welding of Billets}

Immediately prior to billet assembly, both surfaces of the picture frame and the surfaces of the cover plates which contact the picture frame and core are thoroughly vapor degreased and surface oxide is removed by scratch brushing with a power-driven stainless steel brush. The evacuating stem is inserted approxi mately $1 / 8 \mathrm{in}$. into the hole provided in the frame and welded to the frame with type 347 stainless steel filler rod. The tube is purged with an inert gas during welding to prevent melting of the tube wall.

The billet is assembled by stacking the three sub-compacts in the frame hole. Between each sub-compact a foil is placed to improve the compact to compact bonding during hot rolling. To prevent contact of the compacts with the frame and potential reaction of europium oxide with wrought stainless steel, foils are placed around the periphery of the frame hole prior to insertion of the stack of sub-compacts. Foils are placed at the cover platecompact interfaces and held in place by bending the edges of the foil over the sub-compact. After insertion of the compacts, cover plates are placed on top and bottom of the frame and held in place by "C" clamps. The cover plates overhang the frame by approximately $3 / 16$ in. on all sides to facilitate welding.

Cover plates are attached to the frame by heliarc welding. Two heavy weld passes employing a type 347 stainless steel filler rod are made completely around the periphery of the two frame-cover plate joints. All welds are brushed and examined for possible flaws. The sealed billet is subsequently leak tested under water with a 20 pound internal helium pressure applied through the evacuation stem. The blllets are then evacuated to a final vacuum of less than 10 mu as indicated on a thermocouple vacuum gauge. During this operation, the billet is periodically heated to approximately $5000 \mathrm{C}$ to drive off any water vapor and entrapped gases. The Intermittent heating is continued until there is no further indication of loss in vacuum upon reheating at which time the evacuation stem is sealed by hot forging. 
F. Composite Plate Fabrication

1. Hot Rolling

The assembled and evacuated btllets are hot rolled in lots of 2 to a thickness of 0.156 in. \pm 0.002 in, on a two-high Mesta mill equipped with 20-Inch dlameter $\times 30 \mathrm{in}$, wide rolls. However, the lot size is determined by the muffle available for heating the billets. A furnace capable of maintaining $2100^{\circ} \mathrm{F} \pm 250 \mathrm{~F}$ over a muffle length of $40 \mathrm{in}$. is recommended. The muffle is purged from the rear with hydrogen gas with an inlet dewpoint of less than $-50^{\circ} \mathrm{F}$ as measured by an Accurate Dewpointer. A flow rate of 250 cfh is generally used.

The billets are heated to $2100^{\circ} \mathrm{F}$ for at least 90 minutes prior to the first pass, and are reheated for at least 5 minutes between subsequent passes. The reheat time is reduced to 3 minutes between each pass near completion of the hot rolling. A second lot of billets is introduced into the furnace for preheating at the initiation of rolling the preceding billets to allow continuous hot rolling. After the final pass, the plates are replaced in the muffle for a 5 minute anneal, and are then air cooled.

On all billets, the side containing the hot forged evacuation stem is gripped so that the opposite end can enter into the rolls. This practice is continued throughout the hot rolling to assure a single rolling direction, although the billet is rotated 180 degrees about its longitudinal axis between passes. The hot rolling is performed in approximately 22 passes using $10 \%$ reductions in thickness during each pass as indicated by mill settings. Lighter reductions are made, as required, to roll to 0.156 in, \pm 0.002 in. near end of fabrication schedule. The plate thickness is measured over the core area with a micrometer to determine the actual thickness of the hotrolled plate. As the thickness of the plate approaches $0.170 \mathrm{ln}$., core length is measured between subsequent passes with a tape to ensure that the plates are not rolled over-size in length. The core length can be readily measured in this manner since the dispersion-type core can be delineated from the wrought stainless steel by a difference in heat color.

Special care is exercised during rolling to minimize cambering or "rainbowing" of the plates which tends to decrease the amount of stainless steel along the inactive edge in the final machined plate. Cambering of the absorber plate may possibly be corrected, depending on severity, by inserting the plate through the mill at a slight angle. A level mill and proper feeding are recommended to circumvent this difficulty.

After cooling and prior to end trimming the hot-rolled plates are numbered consecutively starting with " 1 " for the first plate processed. Numbers, one-half inch high, are stamped on the inactive Bection at the end op-

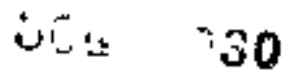


posite the evacuation stem or the leading end of the plate. Care must be exercised to insure that this identification is maintained during subsequent processtng operations. Each number is entered into the record.

\section{Pickling of Hot-Rolled Plates}

After the plates have been properly identtfied, they are sheared on a power-driven shear to a total length of 34 inches. The trailing end of the plate is sheared to within 1-1/2 in. of the core and the remaining wrought stock removed from the leading plate end. The oxide scale which formed during hot rolling and cooling is removed by pickling the plates in an aqueous solution of $5 \mathrm{~g}$ HF and $15 \%$ HNO3. After pickling, the plates are thoroughly washed with water to remove all traces of acid. The plates are then dried and visually examined for surface pitting, oxide scale inclusions, and other possible defects.

\section{Flatten Annealing of Absorber Plates}

To prevent warpage of the absorber plates during subsequent machining and shearing operations, it is necessary that the composite plates be flat and fully annealed. The use of flat plates also facilitates assembling into the required box array. Both the flattening and annealing of the absorber plates is accomplished in a single operation.

Each cleaned plate is covered on one side with a thin coat of a mixture containing one part by volume of Fisher 5F Precisionite levigated alumina and ten parts of water. A three-inch camel's hair brush is used to apply an even coating. The coated plates are allowed to dry for at least 15 minutes. The jig is composed of two platens for clamping the absorber plates together. Six absorber plates are stacked together with the coated side adjacent to the uncoated side. The stack is placed between the platens, and the clamping bolts are firmly tightened. The loaded assembly is dried in an oven at $330^{\circ} \mathrm{F}$ for a minimum of 16 hours.

Annealing is accomplished within an Inconel muffle inserted into a 56$\mathrm{kw}$ Globar furnace at a temperature of $18320 \mathrm{~F} \pm 25^{\circ} \mathrm{F}$. The muffle has a cross-sectional dimension of $7 \times 9$ in. and is 6 feet in length. Bright annealing of the plates is obtained under a purge of dry hydrogen with a dewpoint of $-80^{\circ} \mathrm{F}$ as measured by an Accurate Dewpointer at the furnace inlet.

Furnace temperature at insertion of the loaded platen assembly ordinarily does not exceed $570^{\circ} \mathrm{F}$. The muffle is purged with helium prior to insertion of the plates and during the period between $570^{\circ} \mathrm{F}$ and $1200^{\circ} \mathrm{F}$. At $1200^{\circ} \mathrm{F}$ the helium atmosphere is replaced by dry hydrogen. A flow rate sufficient to bright anneal stainless steel ts recommended; $240 \mathrm{cfh}$ is gen-

$$
\text { SC: } \quad r 31
$$


erally used. The temperature is increased to $1832^{\circ} \mathrm{F}$ at a rate of approximately $540^{\circ} \mathrm{F}$ per hour. The plates are held at $1832^{\circ} \mathrm{F}$ for two hours, and then slowly furnace cooled to $5700 \mathrm{~F}$. At this temperature, the hydrogen atmosphere is replaced with a helium purge; the assembly removed from the furnace; and air cooled. After disassembly, the absorber plates are scrubbed under flowing water to remove the coating of alumina, air dried and inspected again for defects.

\section{Preliminary Machining of Absorber Plate}

To assure a true plate reference edge for radiographically locating the absorber core, it is necessary to machine one edge of the plate. A stack of six plates is edge aligned on the bed of a milling machine and held in position by bar clamps. A series of skim cuts are made to a total depth of approximately $1 / 4 \mathrm{in}$, or until smooth, uniform plate edges are obtained. The edges of the plates are filed to remove machining burrs and the plates are cleaned by vapor degreasing.

\section{Radiography}

The edge machined plates are radiographed to delineate the core on the composite plate for subsequent marking. The plates are positioned on cassettes containing a fine-grained film such as Eastman type " $M$ " and exposed to an X-ray source positioned $\mathbf{5 4}$ inches above the cassette for four minutes. Without using lead filters and with an $X$-ray source power setting of $130 \mathrm{KV}$ and $10 \mathrm{~m}$. a., suitable radiographs are obtained. Normally two radiographs of the plate are taken; the first to obtain over-all dimensions and the second to obtain a clear radiograph of the trailing end of the core.

\section{Marking of Plate for Shearing and Final Machining}

Measurements at three locations along the core length are made and transposed to the plate to delineate the core on the plate surface. The measurements are taken with reference to the machined edge of the plate. After the position of the core is located, the resulting core width is subtracted from the required plate width and the difference equally divided and marked at the three reference locations. These markings serve as the width boundaries during machining to final size. The location of the trailing end of the core is critical since the engineering drawing specifies a minimum of 1/4 in. of inactive stainless steel at this end. The end is located from the radiograph and a mark scribed 1/4 in. from the core end. From this scribe mark, the final plate length of $26-1 / 16$ in. is measured to the opposite end of the plate and a mark scribed.

232 
After the machining reference lines are scribed, additional lines $1 / 8 \mathrm{in}$. outside of the machining lines are located at the ends and along both sides. These lines represent the sheared length and width dimensions. The identifying number is again stamped at the leading end of the plate which contains the nominal 5 in. length of inactive stainless steel within the machining line boundaries.

\section{Shearing of Plates Prior to Machining}

To minimize the amount of wrought stock removal prior to machining, the plates are sheared to within $1 / 8$ in. of the final machining dimensions. The plates are sheared on a power-driven shear suitable for shearing $3 / 16$ in. thick stainless steel. In shearing to width dimensions, the plates are positioned and clamped to the shear table with three bar-type clamps equally spaced along the plate length. Clamping is not required in shearing the plate ends.

\section{Inspection for Core Alignment}

Prior to machining the absorber plate, it is recommended that the core alignment be inspected. The $1 / 8 \mathrm{in}$. excess wrought stock provides ample room for re-alignment if required. The core alignment is inspected by radtographic examination. Radiographs are obtained in the same manner as described in Section $F$, Item 5, except that four plates are positioned on the cassette at one time.

\section{Machining of Absorber Plates to Final Dimensions}

In this operation, it is recommended that a single plate be machined at one time. Each plate is first machined to the final width dimensions. The sheared absorber plate is placed on the table of a vertical milling machine. A 3/-8-in. aluminum plate is positioned between the absorber plate and the table to elevate the absorber plate. Using a dial gauge indicator, the machining scribe marks are aligned with the traverse of the table and held in position by bar-type clamps at the plate ends. Three additional bar clamps are positioned and firmly locked along the plate length in such a manner as to permit machining along one side of the plate. After checking the plate alignment, the plate edge is machined to the scribed line. The three bar clamps are then removed without disturbing the plate and repositioned on the opposite side of the plate. After rechecking the plate alignment, the remaining plate edge is machined to the scribed line. The width dimension is inspected with a mic rometer.

The end of the plate at which the minlmum $1 / 4-\mathrm{in}$. inactive stainless steel end is specifled is likewlse individually machined to the scribed ma-

$$
2+4 \quad r 33
$$


chining mark. This is accomplished after machining the second plate edge by leaving the plate locked in position and removing the appropriate end bar clamp. Six plates which have been machined at the critical end are stacked together, butted against an end plate and gang milled to final length.

After completion of the machining operation, the plates are degreased in a vapor degreaser and the machined edges are lightly deburred by hand filing at a $\mathbf{4 5}$ degree angle.

\section{Final Inspection of Plates}

a. All absorber plates are inspected to ensure that they meet final dimensions. The over-all length, width, and thickness measurements are made with a calibrated straight edge and micrometers, respectively.. The finished machined plates are then radiographed to delineate the inactive stainless steel. Measurements are made from the radiographs to determine acceptance or rejection. Plates with less than 0.080 in. inactive stainless steel at any point along the edges are rejected. Plates with less than 3/16 in. at the end specifying a nominal $1 / 4 \mathrm{in}$. inactive stainless steel are also rejected.

b. Contamination check - The absorber plates will be subjected to an alpha count to determine if any possible surface contamination exists. The plate shall be checked for alpha contamination by means of gas flow proportional counting or a similar method. Alpha contamination equivalent to 0.5 micrograms of U-235 per square foot shall be the maximum allowable level of contamination. It is assumed that one microgram of U-235 per square foot is equivalent to 150 disintegrations per minute per square foot of plate surface.

\section{G. Manufacturing of the Absorber Section}

Immediately priar to assembly, all components are visually inspected. The absorber plates are again degreased to ensure cleanliness.

\section{Assembly Jigs}

Two jigs are required for the assembly of the absorber section. The initial assembly is performed around a solid graphite block. A $1 / 2$ in., 45 degree cut is machined from all corners of this block to prevent contact of graphite and stainless steel during subsequent welding. Final assembly of the section is achieved using a split graphite block. This split block wedge design allows conventent removal after final welding. 


\section{Assembly and Welding of the Section}

The following sequence is recommended for the assembly and welding of the absorber section.

(a) Plate No. 1 serves as the base plate and is positioned on two $1 \times 2$-in. parallel bars equally spaced on a surface plate. The plate end opposite the identifying number is butted against an angle plate.

(b) The solid graphite block is positioned on plate No. 1 and butted against the angle plate. The right side of the block should lie approximately 0.156 in. inside the edge of the base plate.

(c) Plate No. 2 is placed perpendicular to the surface plate with the edge butting the parallel bars and the inner surface butting the edge of plate No. 1. Care is taken to assure that the identifying number is opposite the end of the plate adjacent to the angle plate.

(d) Plate No, 3 is placed perpendicular to the surface plate with the edge butting the inside of plate' No. 1 . To hold the plates in position, "C" clamps are spaced along the length of the assembly. Again, care is exercised to assure that the end opposite the identifying plate number is adjacent to the angle plate.

(e) Plate No. 4 is then placed on top of the graphite block. The right edge of the plate is butted against the inner'surface of plate No. 3 and the inner surface butting the edge of plate No. 2. The position of the numbered end of the plate is again checked to assure proper positioning adjacent to the angle plate.

(f) After irispecting the position of the identifying numbers on each plate, the assembly is rigidly clamped together with 5 -in. " $\mathrm{C}$ " clamps. The end of the section with the 1/4-in. nominal inactive stainless steel is squared against the angle plate. The width and height of the assembly is measured with a micrometer. If dimensions are less than nominal, shims are placed at the proper points to increase the dimensions to $2.619 \mathrm{in}, \pm 0.010 \mathrm{in}$.

(g) After proper dimensions have been established, the joints be - . . tween plates No. 1 and No, 2 and No, 1 and No, 3 are heliarc welded. These joints are first tack welded at the corners. The welds are made in conformance with the procedure previously established in qualification. Three-tnch-welds are initiated at the corners and continued inward and are staggered from di:-

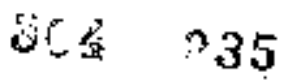


agonally opposite corners until the entire joints are completed. No filler rod is used during the welding operation.

(h) Upon cooling to room temperature, the "C" clamps are removed from the assembly and the top plate (No. 4) and the solid graphtte.jig are removed.

(i) The split, wedge-shaped jig is inserted into the partially welded absorber section. The two wedge-shaped blocks are fitted together to forma rectangle with over-all dimensions of $1.80 \mathrm{x}$ $2.307 \times 30$ in. Since the width of this jig is $1 / 2$ in. narrower than the solid graphite jig, it is centered in the partially welded section with a 1/4-in. clearance between the sides of the jig and the absorber plates.

(1) The top plate or plate No. 4 is replaced on top of the split jig with its right edge butting the inner surface of plate No. 3 and its inner surface butting the edge of plate No. 2. Care is taken to identify the position of the numbered plate end. After squaring the end of the section with the 1/4-in. inactive edges, it is secured in place with 5-in. "C" clamps. The dimensions of the assembly are carefully checked with a micrometer to insure conformance to drawing.

(k) The remaining plate joints between plates No. 2 and No. 4 and No. 3 and No. 4 are then heliarc welded in the same manner as described in Item $\mathbf{G}$.

(1) While the welded absorber section is still warm, the clamps are released and the split-graphite block is removed by gently tapping an end of one of the wedges.

(m) All welds are brushed and inspected for weld defects.

\section{Attachment of Handle}

Prior to attachment of the handle, the entire inner surface of the absorber section is scratch brushed with a long-handled stainless steel brush to remove graphite particles and surface oxide. A hole is drilled through one side of the stainless steel absorber section in accordance with the absorber assembly drawing. The end containing the identifying plate numbers is centered on a drill press table and a 3/8-in. diameter hole drilled through the two absorber plates. A holder pin machined to specifications is then placed in the drilled hole, with approximately a 1/16-in. recess on both absorber plate outer surfaces. The pin is attached by heliarc welding, using type 347 stainless steel filler rod.

$$
\text { نं }
$$




\section{H. Cleaning of Absorber Section}

The assembled absorber section is cleaned to remove all excess weid metal and discoloration. Removal of the excess weld material and discolor - : ation is accomplished by abrading the entire outer surfaces of the section with fine-grained emery paper or a rotary stainless steel brush. The edges of the absorber are then rounded to a radius of approximately $1 / 32$ in. by hand filing. Upon completion of the mechanical cleaning, the absorber is wiped with a cloth containing a small amount of kerosene to remove the fine metal fllings. The kerosene is removed by degreasing in a vapor degreaser.

I. Numbering Absorber Sections

A number $5 / 16$ in. in height is stamped on each plate 1 in. from the end of the absorber which has the nominal 5-in. length of inactive stainless steel. The absorbers are numbered serially, starting with No. 1 and progressing to sequentially higher numbers. A wooden block insert, positioned in the end of the absorber to be marked, prevents possible warpage or deforming of the section during stamping. The appropriate records are entered into the record.

J. Visual and Dimensional Inspection

The assembled absorber ts inspected visually for possible flaws such as pits, surface scratches, indentations; and improper welds in accordance with qualification requirements.

The cross-sectional width, length and squareness of each absorber is dimensionally inspected. The cross-sectional width of the absorber is measured with a 3-in. micrometer at five locations along the length. Two meassurements, 90 degrees apart, are taken along the center line of the section at distances of 1, 6, 13, 19 and 26 in. from the critical end of the absorber. The measurements of each absorber are recorded on an appropriate inspection record. Absorbers with width dimensions outside the limits of 2.619 in. $\pm 0,010 \mathrm{in}$, are rejected.

The absorber length, measured with a calibrated straight edge, must be within the required specification of $26-1 / 16 \mathrm{in} . \pm 1 / 16-1 \mathrm{n}$.

The absorber is checked for squareness on a surface plate. Any evidence of twist or other manifestation of out-of-squareness requires that the section be subjected to insertion through the final inspection box. This box is designed with internal dimensions of $2,650 \times 2.650$ in. and $26-1 / 16$ in. long. Binding at any point during this test is cause for rejection. 
K. Preparation for Shipment

Prior to storage and/or shipment, the absorbers are vapor degreased and enclosed in a plastic sheath which is thermally sealed to protect the component. The absorbers are packaged in shipping containers which are designed to prevent damage during shipment.

5. 


\section{APPENDIX}

The following forms are illustrated to serve as a guide in helping potential fabricators maintain proper metallurgical history, and other pertinent data requiring permanent record:

1. Rare Earth Powder Metallurgy Core Order Form

2. Powder Metallurgy Fabrication Form

3. Absorber Plate Fabrication Record

4. Radiographic Inspection Sheet

5. Absorber Assembly and Inspection Sheet 


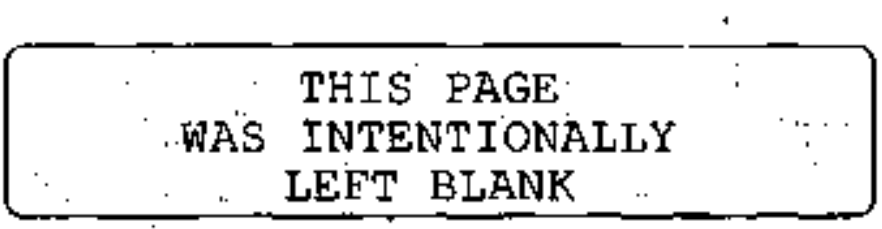




\section{RARE-EARTH POWDER METALLURGY CORE ORDER FORM}

Core Order * Order Date

No. of Cores Ordered Order Completed

Rare-Earth Specifications per core:

1. Type material

2. Identification

3. Weight per cent

4. Grams per core

5. Particle size

Matrix Material Specifications per core:

1. Type material

2. Base constituents

3. Identification of Constituents

4. Weight per cent

5. Grams per core

6. Particle size

Theoretical Total Core Weight, grams

Desired Core size

Special Instructions 


\section{RARE-EARTH POWDER METALLURGY CORE ORDER FORM}

Data for Core Order *

A. Blending Operation

1. Identification of blending container:

2. Blending device to be used:

3. Blending time desired:

Spectal Instructions:

B. Core Processing Operations

1. Initial cold pressing operation:
a. Pressure tsi
b. Load $\mathbf{T}$

2. Initial sintering operation:
a. Atmosphere
, dew point
${ }^{\circ} \mathrm{F}$
b. Sintering time $\mathrm{hr}$, Temperature o F

3. Final pressing operation:

a. Pressure ___

b. Load $\mathbf{T}$

4. Final sintering operation:
a. Atmosphere
, dew point
${ }^{\circ} \mathbf{F}$
b. Sintering time $h r$, Temperature ${ }^{\mathbf{0}} \mathbf{F}$

5. Coining operation:
a. Pressure tst
b. Load $T$

6. Other operations: 
RARE-EARTH POWDER METALLURGY CORE ORDER FORM

Data for Core Order

Deviations from the specified core composition or fabrication procedure:

Record of Individual core welght and thickness:

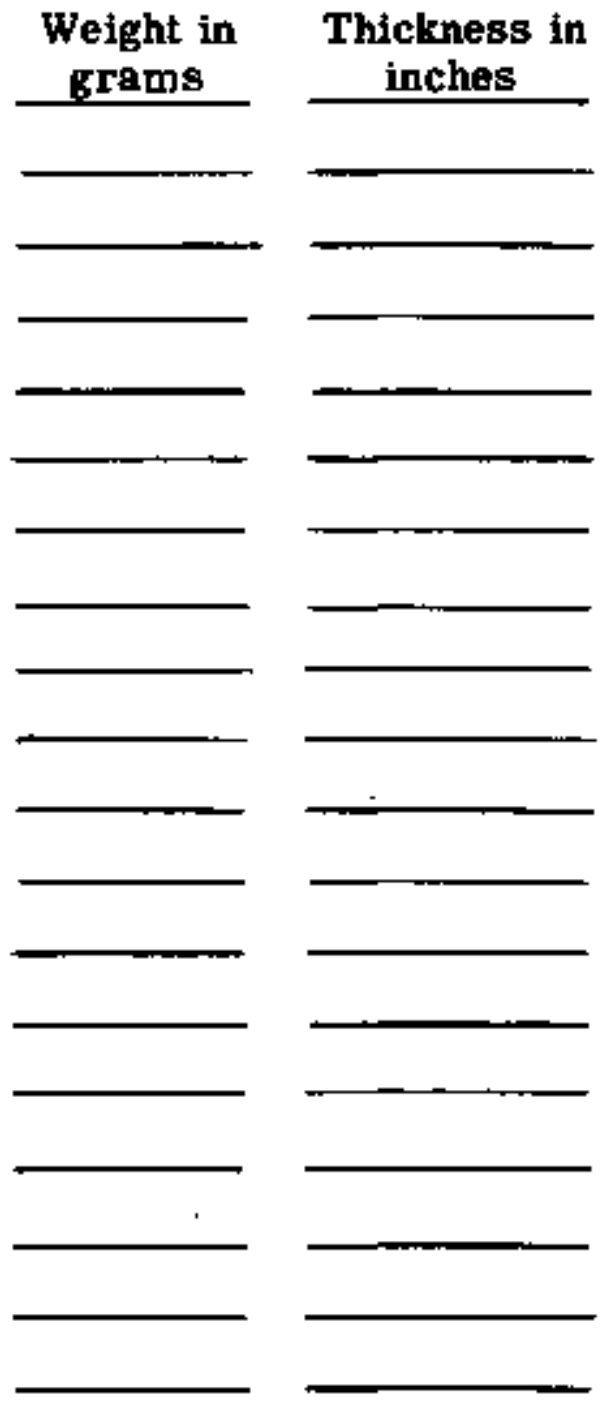

Average core Weight

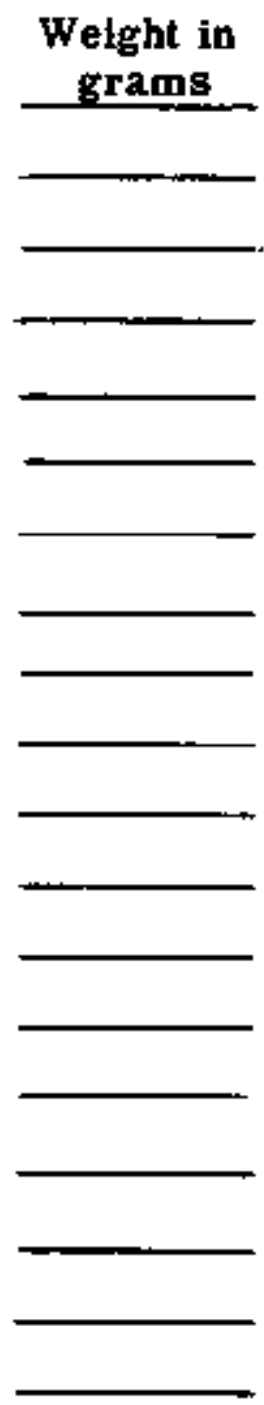

Thickness in inches

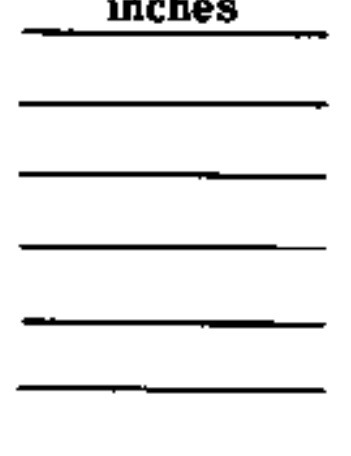

Average core Thickness

No deviations from the specified core composition or fabrication procedure are to be made without the prior approval of 


\section{POWDER-MET FABRICATION FORM}

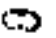

4

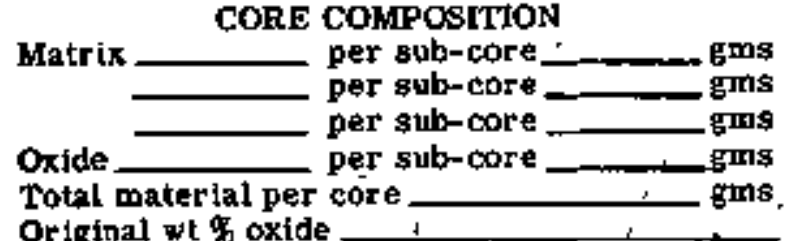

Original wt oxide $^{2}$

\begin{tabular}{|c|c|c|c|c|c|c|c|c|c|c|}
\hline $\begin{array}{l}\text { No. Cores } \\
\text { in Bateh }\end{array}$ & $\begin{array}{l}\text { Total Oxide } \\
\text { in Bateh }\end{array}$ & $\begin{array}{l}\text { Total } \\
\text { Batch Wt } \\
\text { (A) }\end{array}$ & $\begin{array}{c}\text { Total } \\
\text { Batch Wt } \\
\text { After } \\
\text { P ressing } \\
\text { (B) }\end{array}$ & $\begin{array}{l}\text { Batch Wt } \\
\text { Loss } \\
\text { (A-B) }\end{array}$ & $\begin{array}{l}\text { Average Wt } \\
\text { Loss per } \\
\text { Sub-core }\end{array}$ & $\begin{array}{l}\text { Number Cores } \\
\text { Accepted }\end{array}$ & $\begin{array}{l}\text { Average Wt } \\
\text { Loss per } \\
\text { Acceptable } \\
\text { Core }\end{array}$ & $\begin{array}{c}\text { Number Cores } \\
\text { Rejected }\end{array}$ & $\begin{array}{l}\text { Reason for } \\
\text { Rejectlon }\end{array}$ & $\begin{array}{c}\text { Recelved } \\
\text { By }\end{array}$ \\
\hline & & & & & & & & & & \\
\hline & & & & & & & & & & \\
\hline & & & & & & & & & & \\
\hline & & & & & & & & & & \\
\hline & & & & & & & & & & \\
\hline & & & & & & & & & & \\
\hline & & & & & & & & & & \\
\hline & & & & & & & & & & \\
\hline & & & & & & & & & & \\
\hline & & & & & & & 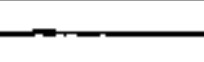 & & & \\
\hline & & & & & & & & & & \\
\hline & & & & & & & & & & \\
\hline & & & & & & & & & & \\
\hline & & & & & & & & & & \\
\hline & & & & & & & & & & \\
\hline & & & & & & & & & & \\
\hline & & & & & & & & & & \\
\hline & $\because$ & & & & & & & & & \\
\hline & & & & & & & & & & \\
\hline & i & & & & & & & & & \\
\hline
\end{tabular}

Lot Number

Type Materia]

Total Matertal

$\therefore$ 
ABSORBER PLATE FABRICATION RECORD

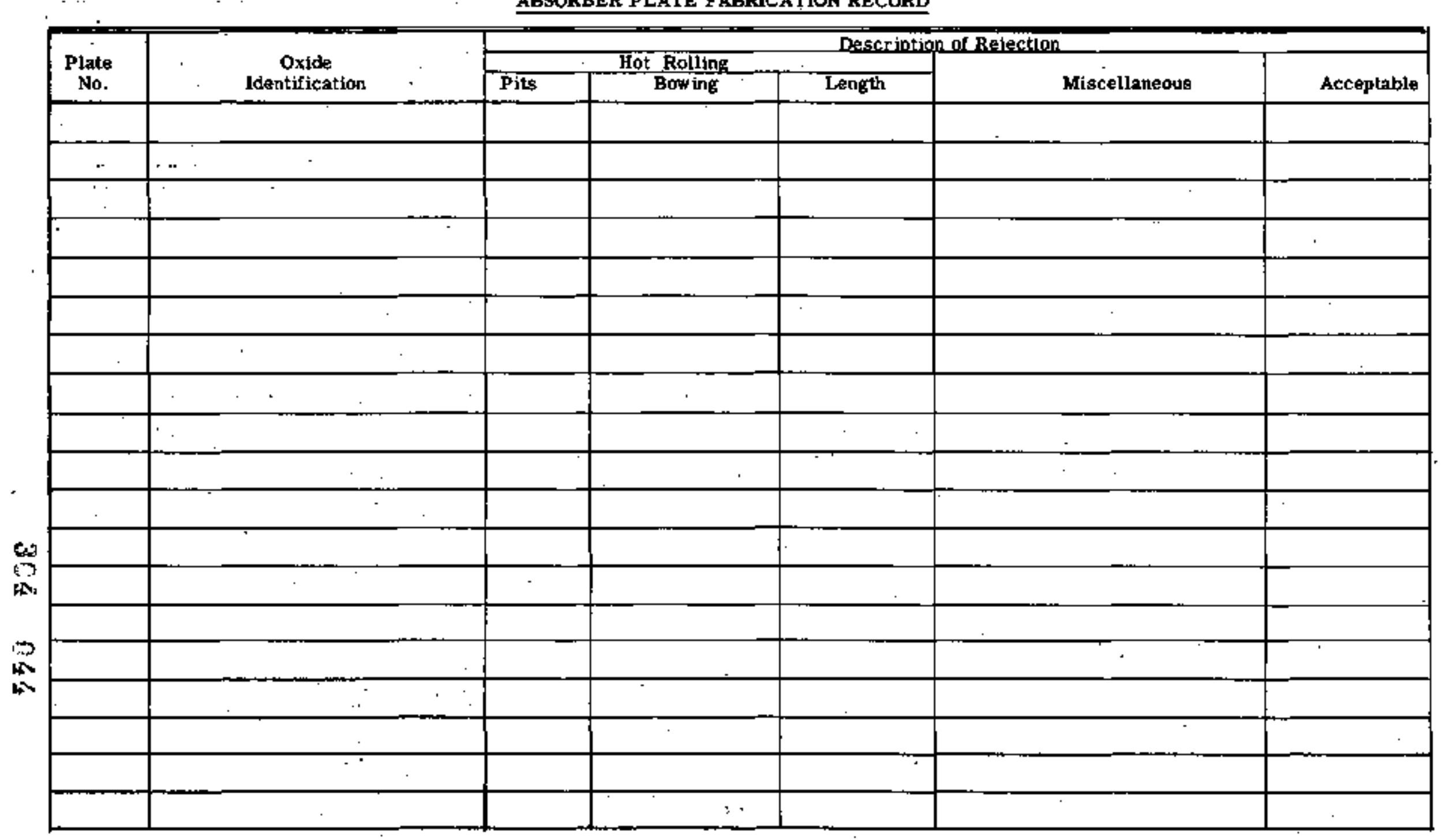




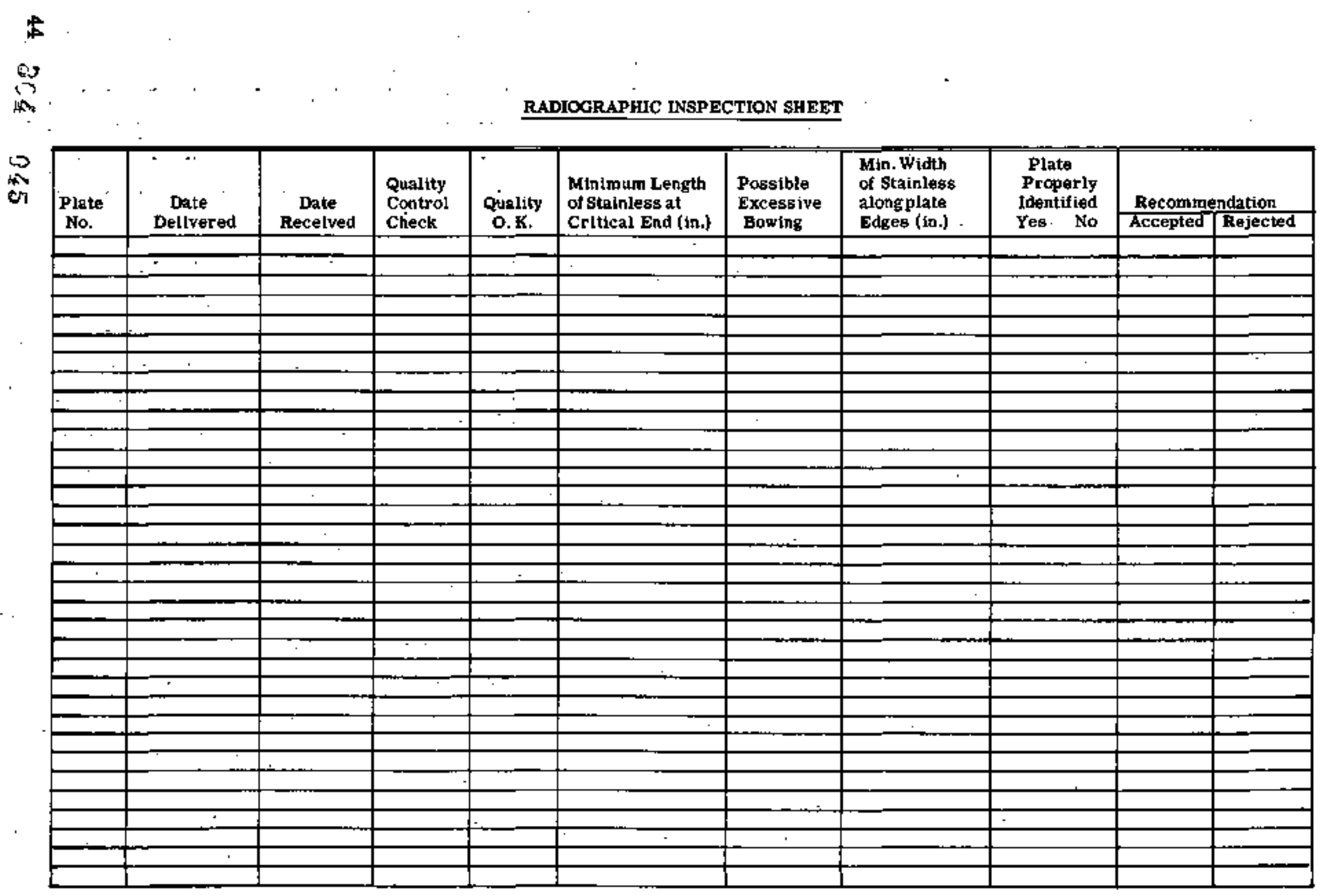




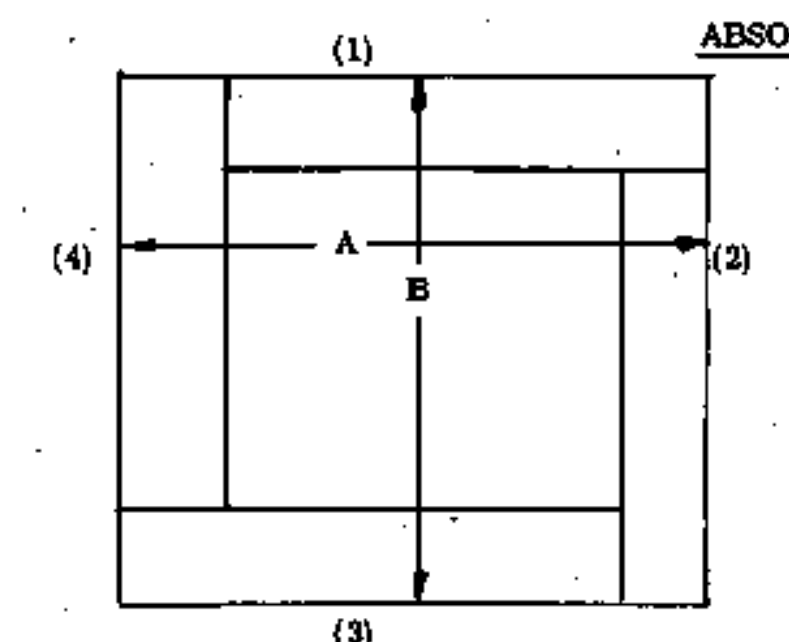

(3)

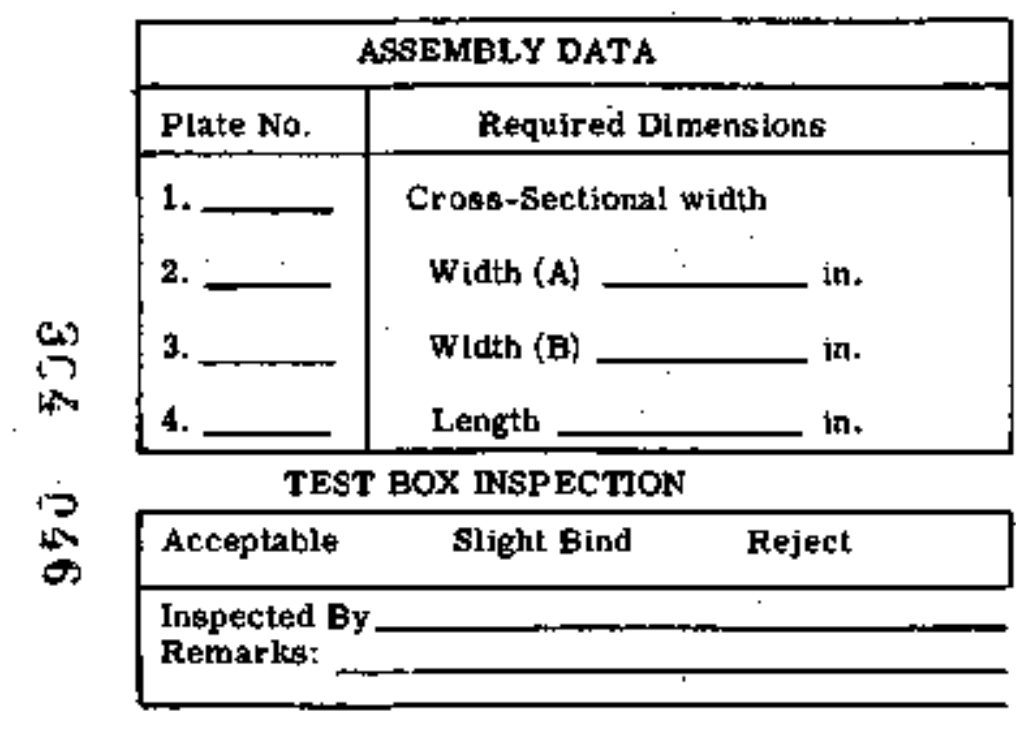

Type Unit Destination

\begin{tabular}{|r|r|r|r|r|r|r|r|}
\hline \multicolumn{7}{|c|}{ INSPECTION DATA } \\
\hline \multicolumn{7}{|c|}{ Cross-Sectlonal width Measurements } \\
\hline \multicolumn{5}{|c|}{ Width (A) ([n.) } & \multicolumn{3}{c|}{ Width (B) (In.) } \\
\hline Locatlon & Top & Middle & Bottom & Location & Top & Middle & Bottom \\
\hline 1 & & & & 1 & & & \\
\hline 6 & & & & 6 & & & \\
\hline 13 & & & & 13 & & & \\
\hline 19 & & & & 19 & & & \\
\hline 25 & & & & 25 & & & \\
\hline
\end{tabular}

Average width (A)__

Average Wldth (B)

- in. +

\begin{tabular}{|l|l|l|l|l|l|}
\hline \multirow{2}{*}{ Postion } & $\begin{array}{c}\text { Length } \\
\text { Inches }\end{array}$ & \multicolumn{4}{|c|}{ Visual Inspection } \\
\hline Edge & & Discontinuous weld & & & \\
\hline Center & & Weld Cracking & & & \\
\hline Edge & & $\begin{array}{c}\text { Excessive wejd } \\
\text { Acceptable } \\
\text { surface condition }\end{array}$ & & & \\
\hline & & Miscellaneous & & & \\
\hline
\end{tabular}

\section{ABSORBER FABRICATION RECORD}

$\therefore$ Shlpped

Identification Number 


\section{DRAWINGS}

Absorber Section Assembly

Absorber Plates

Pin
Alco Drawing D9-13-2094 Rev. B.

Alco Drawing D9-13-2092 Rev. B A9-13-2093

Alco Drawing A9-13-2019 Rev. B 


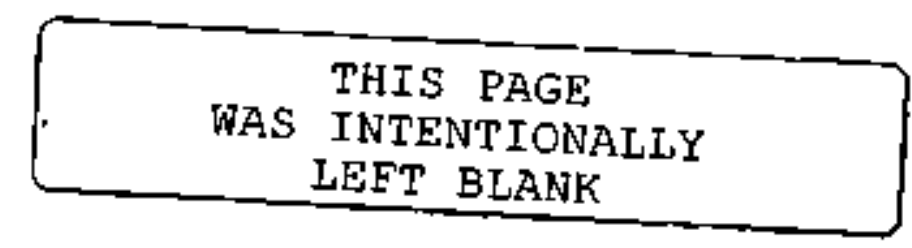




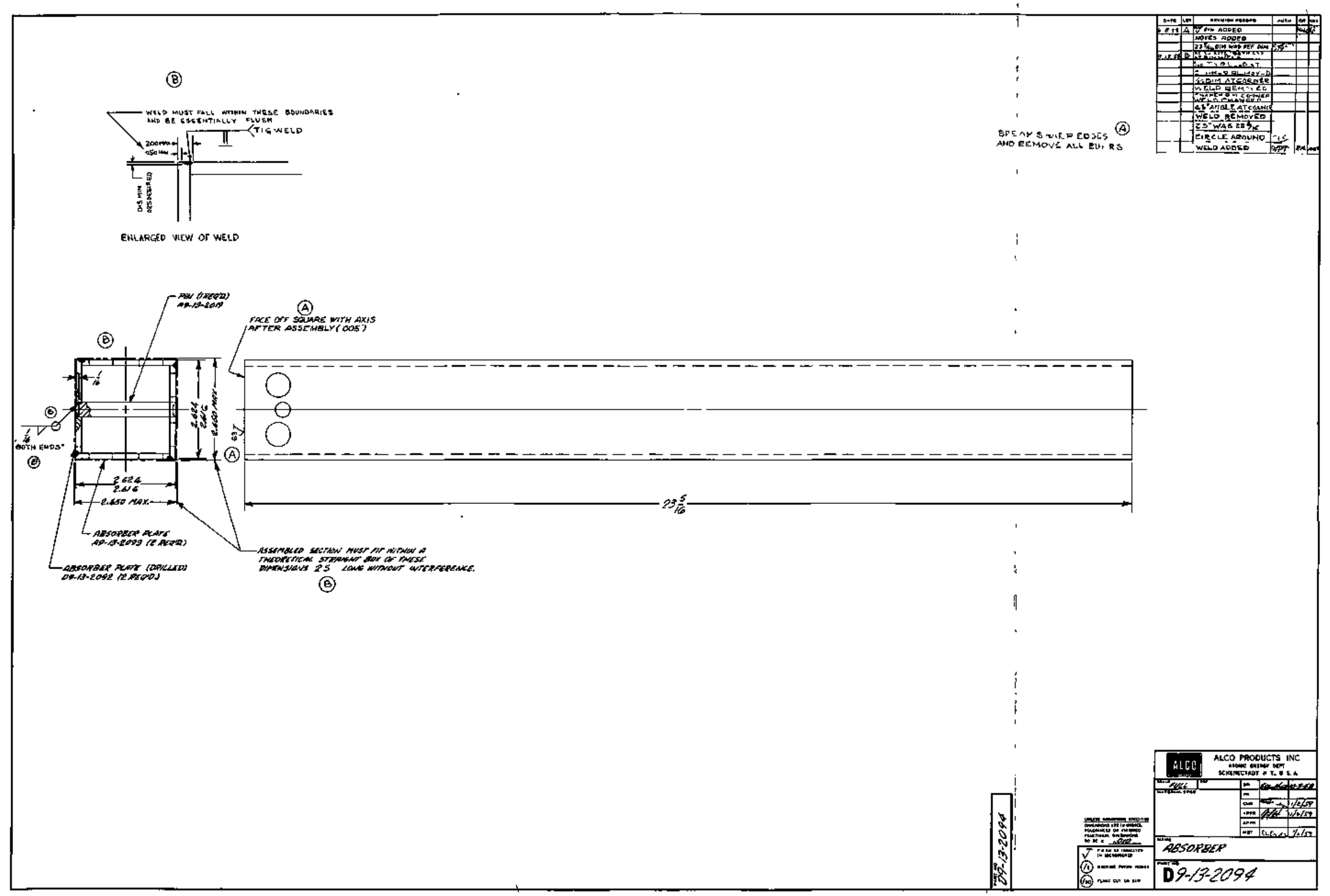





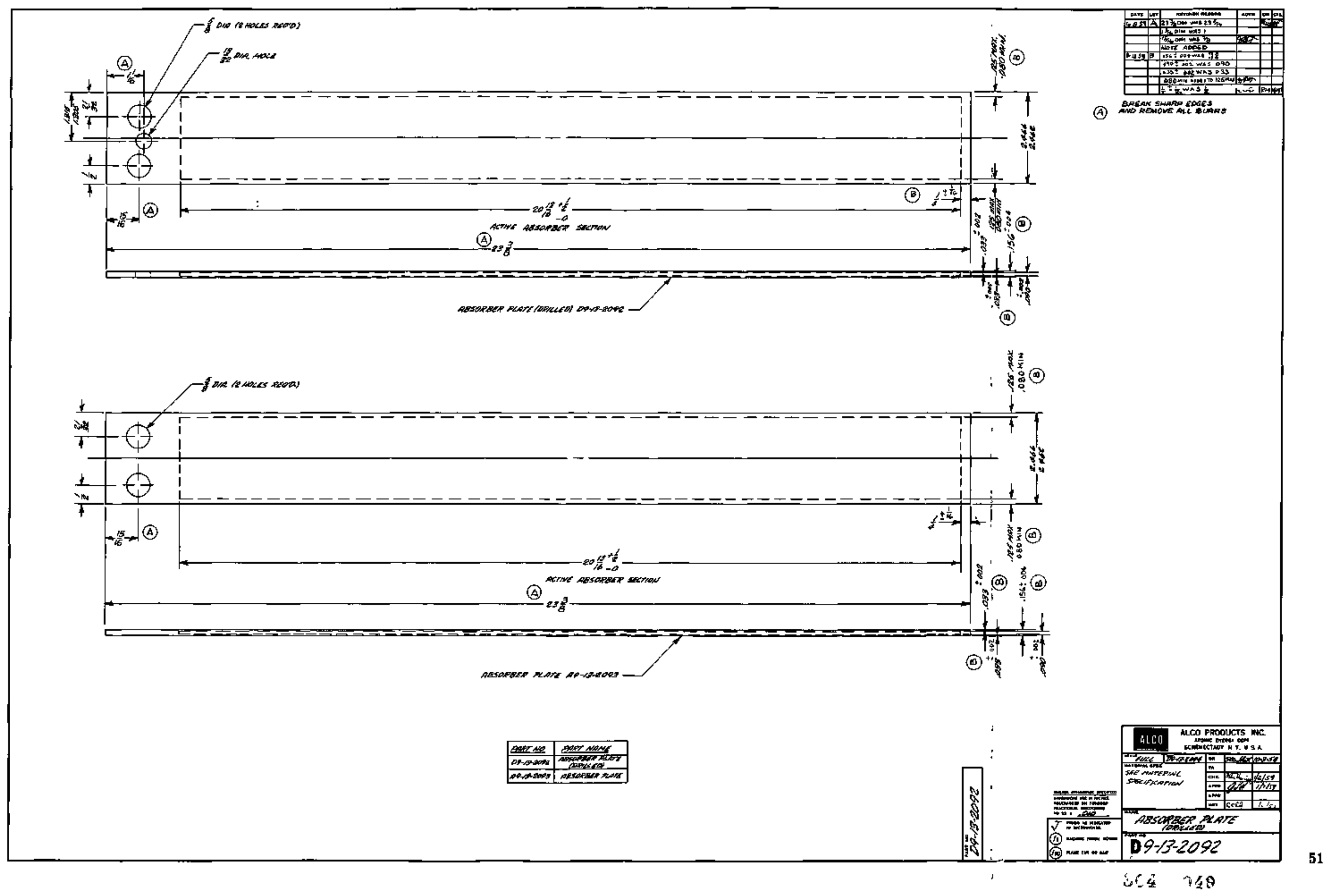





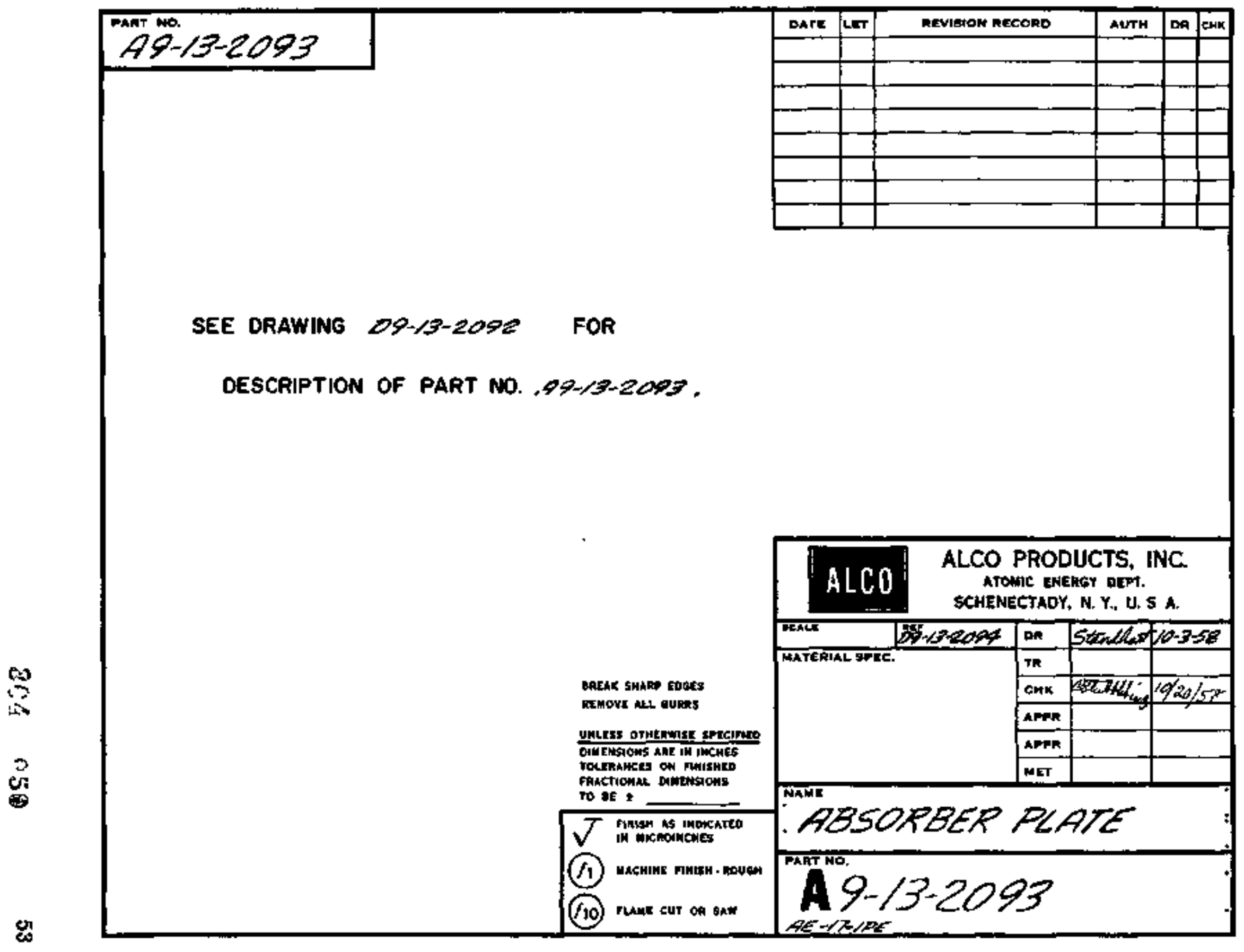


THIS PAGE

WAS INTENTIONALLY

LEFT BLANK 


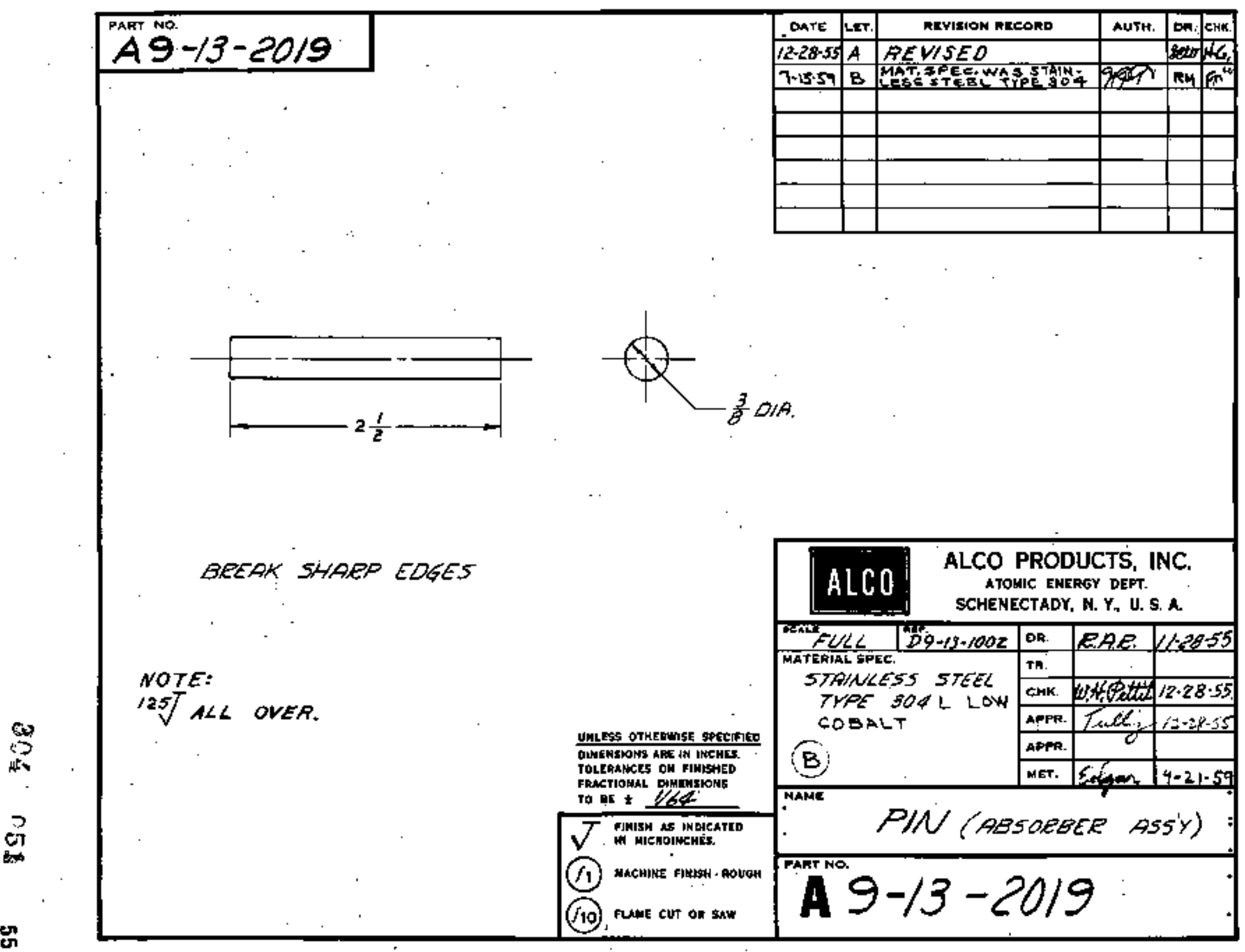

